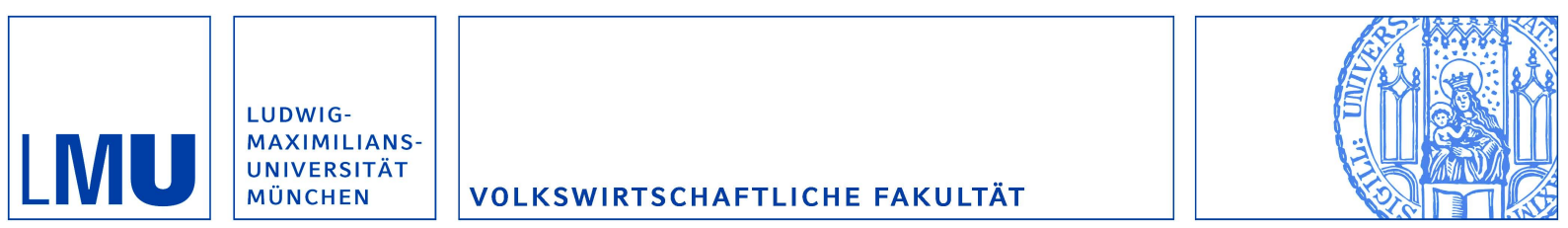

Buchheim, Lukas und Kolaska, Thomas:

Weather and the Psychology of Purchasing

Outdoor-Movie Tickets

Munich Discussion Paper No. 2016-1

Department of Economics

University of Munich

Volkswirtschaftliche Fakultät

Ludwig-Maximilians-Universitäł München

Online at https://doi.org/10.5282/ubm/epub.26930 


\title{
Weather and the Psychology of Purchasing Outdoor-Movie Tickets
}

\author{
Lukas Buchheim Thomas Kolaska*
}

\begin{abstract}
January 12, 2016
The consequences of many economic decisions only materialize in the future. To make informed choices in such decision problems, consumers need to anticipate the likelihood of future states of the world, the state-dependence of their preferences, and the choice alternatives that may become relevant. This complex task may expose consumers to psychological biases like extrapolative expectations, projection bias, or salience. We test whether customers are affected by such biases when they buy advance tickets for an outdoor movie theater, a real-world situation that, due to the availability of reliable weather forecasts, closely resembles a stylized decision problem under risk. We find that customers' decisions are heavily influenced by the weather at the time of purchase, even though the latter is irrelevant for the experience of visiting the theater in the future. The empirical evidence cannot be fully explained by a range of candidate rational explanations, but is consistent with the presence of the aforementioned psychological mechanisms.
\end{abstract}

Keywords: Projection Bias, Salience, Extrapolative Expectations, Behavioral Economics, Consumer Behavior

JEL Classification: D03, D12, D81

*Department of Economics, University of Munich, Geschwister-Scholl-Platz 1, 80539 Munich, Germany; Lukas Buchheim: lukas.buchheim@econ.lmu.de; Thomas Kolaska: thomas.kolaska@gmail.com. We are indebted to Peter Mopils for providing us his sales data. For useful comments, we thank the Associate Editor, two anonymous referees, Jen Brown, Florian Englmaier, David Laibson, Devin Pope, Marta Serra-Garcia, Uwe Sunde, Joachim Winter, and seminar participants at the Universities of Munich and Warwick, the Workshop "Natural Experiments and Controlled Field Studies" in Holzhausen/Ammersee, the 6th "Nordic Conference" in Lund, the IMEBE 2012 in Castellón, the SMYE 2012 in Mannheim, the "Jahrestagung des Vereins für Socialpolitik 2012" in Göttingen, the "Annual Conference of the Royal Economic Society 2013" in London, and the IIOC 2013 in Boston. Financial support from the Deutsche Forschungsgemeinschaft through SFB/TR 15 (Lukas Buchheim) and GRK 801 (Thomas Kolaska) is gratefully acknowledged. 


\section{Introduction}

The consequences of many economic decisions only materialize in the future. Examples of such decision problems include weekly grocery shopping, planning a summer vacation months ahead, as well as making investment decisions that may have profound effects on living standards later in life. The standard model of rational behavior assumes that individuals facing such decision problems maximize their expected utility, implying that individuals are both aware of all the relevant choice alternatives and capable of correctly anticipating their future consequences. The model also implies that the state of the world at the time of decision making is irrelevant for the choices made, as long as today's state is not linked to future outcomes of interest. In contrast, recent psychological models suggest mechanisms through which current conditions may nevertheless affect intertemporal decisions. For example, one strand of the literature argues that individuals have the tendency to overestimate the degree to which future states resemble the current one, either due to extrapolative expectations (e.g. Fuster et al., 2010; Barberis et al., 2015) or due to projection bias (Loewenstein et al., 2003). Another strand of the literature puts forward the argument that the salience of choice alternatives or future contingencies may depend on the choice context at the time of decision making (e.g. Bordalo et al., 2012, 2013; Koszegi and Szeidl, 2013).

In this paper, we test whether the conditions at the time of the decision affect choices in an environment in which it is particularly transparent that only future states matter for the experienced utility. We study online advance ticket orders of an outdoor movie theater. These advance tickets are only valid for one specific movie night, so that the utility from visiting the outdoor theater mainly depends on the conditions on the day of the movie.

As one might expect, the utility of watching a movie outdoors seems to be highly dependent on the weather. One indication for this is that ticket sales on the day of the movie night, when there remains little uncertainty about the weather during the show, are highly correlated with current weather, but cannot be explained by the general popularity of the movie (as measured by box office sales for indoor movie theaters). Predicting their future weather-related utility should hence be an important task for customers who consider purchasing their tickets in advance. This is even more so, because the weather at the theater's location is highly variable and because the accompanying weather risk is fully borne by customers whose tickets are only valid for one specific movie night. This risk is prominently pointed out on the ticketing website, so that customers can be expected to be fully aware of it when they make their decisions. ${ }^{1}$ Note, moreover, that the weather risk is measured by free and unbiased weather forecasts, so that this real-world decision problem comes fairly close to a standard stylized decision problem under risk (as opposed to a decision problem under Knightian uncertainty).

Despite the simplicity of the decision problem, we find that customers are overly influenced by

\footnotetext{
${ }^{1}$ On the website, this is stated as follows: "There are two issues you should be aware of [when ordering tickets]. First: We are going to show the movie regardless of weather conditions. Second: You have to pay for your tickets even if you [decide to let them expire] by not picking them up at the call window." (authors' translation from https://www.didax.de/kms/index.php [22 November 2013]).
} 
the current weather when ordering their advance tickets. We show that ticket orders are 40 to 50 percent higher on a day with completely clear skies than on a completely cloudy day. This finding holds regardless of the purchase horizon, that is, regardless of whether tickets are ordered between one and four days or up to four weeks in advance. Reinforcing the interpretation that current, as opposed to recent, weather conditions affect decisions, we also show that the effect of sunshine duration on ticket orders is present for short-run weather fluctuations, as hourly changes in sunshine duration cause hourly changes in ticket sales. In addition to the effect of sunshine, rainfall on the day of purchase seems to exert a (negative) effect on ticket orders.

We rule out potential explanations for these findings that are consistent with the standard model of rational decision making under risk. First, we show that the weather on the day of purchase has at most negligible predictive power for the weather on the day of the movie. ${ }^{2}$ The current weather thus does not constitute an informative signal for future weather. Second, we argue that a "precautionary" rationale for purchasing tickets in times of good weather cannot explain the weather dependence of ticket orders. The idea is that good weather on a given day may increase the perceived probability for the theater to sell out. If this were the case, good weather would cause customers to purchase their tickets earlier. However, the data contains no evidence of such short-run substitution of ticket orders across days. If a precautionary rationale was driving ticket orders, we would moreover expect current weather to have no effect on very early ticket orders or on hourly variation in sales, as the perceived probability of the theater's selling out is unlikely to vary with weather in these domains. Third, we consider the possibility that inexperienced customers use current weather conditions to learn about their utility of visiting the theater under different weather conditions. Yet, it is unlikely that our results are primarily driven by learning, as ticket orders of repeat customers react similarly, if not more strongly, to current weather conditions than the ticket orders of the average customer. Interestingly, this also holds for customers who had experienced rainfall during a previous movie night and could thus have learned from unpleasant surprises.

Next, we discuss psychological mechanisms that may be able to explain our findings. The first set of theories we consider suggests that good weather leads customers to overvalue their future utility, either due to projection bias or extrapolative expectations. The second set of theories argues that current weather conditions either remind customers of the option of visiting the theater or increase the salience of weather-related product attributes. We propose to use the fact that movie tickets are perishable to distinguish between the hypothesis that weather affects the salience of product attributes from the other three psychological mechanisms. The idea is that customers who, at times of good weather, focus on the favorable good weather attributes of visiting the movie theater, should only be more inclined to buy tickets if the weather outlook for the day of the movie was sufficiently good. We test whether the weather dependence of ticket orders is indeed conditional on expected future conditions by exploiting variation in expected movie-date weather;

\footnotetext{
${ }^{2}$ For brevity, we will refer to the weather on the day of purchase as "purchase-date weather" and to the weather on the day of the movie as "movie-date weather" in the remainder of the paper.
} 
we find that the evidence is predominantly in line with an unconditional effect of weather on sales. The remaining three psychological mechanisms are consistent with all our empirical findings.

Our paper is part of the growing literature that takes behavioral models to field data (see DellaVigna, 2009, for an overview). The articles most closely related to ours are Conlin et al. (2007) and Busse et al. (2015), who study how weather affects the purchasing behavior for durable goods. Conlin et al. (2007) point out that the overvaluation of a good at the time of purchase should lead to a higher fraction of customers who regret their choices ex post. They confirm this hypothesis by showing that customers who purchased winter apparel at times of cold weather are subsequently more likely to return those items. After ruling out a number of alternative explanations, they conclude that their results can be interpreted as evidence for projection bias. Busse et al. (2015) demonstrate that customers are more likely to buy convertibles in times of warm and sunny weather, and are more likely to opt for a four-wheel drive vehicle right after a snow storm. They thus convincingly show that projection bias and/or salience may play a role in high-stakes decisions. This paper complements this earlier work by finding similar results in a study of the purchasing behavior for a perishable good, where the decision problem closely resembles a standard expected utility maximization problem under risk.

The remainder of the article proceeds as follows. The next section describes our data. Section 3 provides a simple graphical analysis of our main results, and proceeds to discuss the identification strategy as well as the main empirical results. In Section 4, we evaluate explanations for our results consistent with rational behavior. In Section 5, we first follow the approach of Conlin et al. (2007) and show that customers who had purchased their tickets during beautiful weather are more likely to let their tickets expire later on. We interpret this as an additional indication for psychological mechanisms driving our results. Subsequently, we discuss these mechanisms and their empirical implications in depth. Section 6 concludes.

\section{Data}

In this section, we describe the data that we use for the empirical analyses in the remaining sections.

\subsection{Weather and Forecast}

Due to the proximity of the Alps, the weather in Munich is highly variable during the season of the outdoor theater, which typically covers the months of June to August. ${ }^{3}$ This manifests itself in high monthly precipitation during the summer months, when total precipitation is on average 123 mm per month (for comparison: London $51 \mathrm{~mm}$, New York City $92 \mathrm{~mm}$, and Berlin $61 \mathrm{~mm}$ ). ${ }^{4} \mathrm{In}$ addition, long periods of stable good weather are the exception. Rather, there are frequent shifts in weather conditions: on average, there are 12.4 rain days (days with at least $1 \mathrm{~mm}$ of rain) per

\footnotetext{
${ }^{3}$ See Section 2.1 for an empirical analysis of the predictive power of current for future weather.

${ }^{4}$ Sources of long term monthly averages: World Meteorological Organization http://worldweather.wmo.int/en/home.html [4 October 2012].
} 
Table 1: Summary Statistics: Weather and Forecast

\begin{tabular}{lccc}
\hline & \multicolumn{3}{c}{ Weather } \\
\cline { 2 - 4 } & All day & Evening & SD within day \\
\hline \multirow{2}{*}{ Avg. Sunshine Duration } & 0.53 & 0.47 & 0.20 \\
& $(0.34)$ & $(0.38)$ & $(0.14)$ \\
Avg. Rainfall per Hour & 0.11 & 0.19 & 0.28 \\
& $(0.24)$ & $(0.63)$ & $(0.63)$ \\
Avg. Temperature & 18.98 & 19.14 & 3.02 \\
& $(3.89)$ & $(4.24)$ & $(1.28)$ \\
\hline & \multicolumn{2}{c}{ Forecast } \\
\cline { 2 - 3 } & Minimum & Maximum \\
\hline Temperatures Forecast & 12.66 & 23.56 & $(4.02)$ \\
& $(2.75)$ & \multicolumn{3}{c}{} \\
\hline
\end{tabular}

Notes: We report means and standard deviations (in parentheses) of the variables. Sunshine duration is measured as a fraction of an hour, temperature is measured in degrees Celsius, and rainfall is measured in mm per hour. In the column "SD within day" we report the average of the variable's standard deviations across hours within a single day.

month between June and August (London 10.5 days, New York City 8 days, and Berlin 8.7 days).

For our empirical analyses, we use high quality weather data from the weather station of the Meteorological Institute of the University of Munich. The data includes hourly measures of sunshine duration (a meteorological measure of the fraction of an hour during which direct solar irradiance exceeds a threshold value), rainfall (measured in mm per hour), and temperature (in degrees Celsius). For most analyses, we use daily averages of these weather variables. For the average of sunshine duration, we restrict attention to hours between 8 am and $7 \mathrm{pm}$ in order to not confound the measure by the changing times of dusk and dawn.

Further evidence concerning the instability of the local weather in Munich is contained in the summary statistics of the weather variables in Table 1 . The between-day variation in weather can be read from the first two columns. The first column reports the average sunshine duration between 8 am and 7 pm as well as 24 hour averages of hourly rainfall and temperature. The second column reports the average sunshine duration in the early evening (between $5 \mathrm{pm}$ and $7 \mathrm{pm}$ ) as well as average hourly rainfall and temperature during the hours during which the movie is usually shown (between $7 \mathrm{pm}$ and $11 \mathrm{pm}$ ). The coefficients of variations (CV) for both sunshine duration (CV equal to 0.64 ) and rainfall (CV equal to 2.18) are relatively large. In addition, note that in the evening average precipitation per hour is almost twice as high as for the entire day. To further gauge the extent of within-day variation of weather, we report the mean of the within-day (i.e., across hours) standard deviations of all weather variables. Again, sunshine duration and precipitation exhibit high within-day variation. ${ }^{5}$

To control for the weather forecast, we hand collected the forecast from the archives of the daily

5 The within-day variation of temperature should be interpreted with caution due to the cyclical pattern of temperature over the day. 
newspaper Süddeutsche Zeitung, which is published every day except Sundays and public holidays. It provides a regional forecast for each day, one to four days into the future, for the greater Munich area. The forecast includes forecast maximum and minimum temperatures (in degrees Celsius) and one of the following weather symbols: sunny, partly sunny, scattered thunderstorms, shower, and rain. ${ }^{6}$ The summary statistics of minimum and maximum forecast temperatures are displayed in Table 1. As expected, they are in a similar range as the average temperatures. The distribution of forecast symbols, which does not vary substantially by forecast horizon, is again indicative of the variability of weather in Munich during the summer: rather unstable weather conditions like scattered thunderstorms (11 percent of the days) and showers (42 percent of the days) are forecasted for more than half of the days in our sample. Sunny or partly sunny conditions are forecasted for 44 percent of the days and rain is forecasted for 3 percent of the days.

\subsection{Ticket Sales}

The data on ticket sales were provided by Kino, Mond und Sterne [Movies, Moon, and Stars], one of four outdoor movie theaters in Munich. The theater has a total of 1,300 seats available, tickets for which are sold at the box office and various advance ticket sales locations. Because the movie is shown regardless of weather conditions, tickets are non-refundable: customers who buy their ticket in advance hence bear the full weather risk.

Our dataset comprises all online ticket orders between 2004 and 2011. For each order, the system records the number of tickets purchased, the exact date of the transaction, the birth date of the customer, as well as a unique alphanumeric customer ID which allows us to track repeat customers. ${ }^{7}$ Online sales constitute a substantial fraction of total ticket sales. Between the years 2009 and 2011, for which we know the overall number of sales, online sales amount to 24 percent of total sales. More than half (almost 60 percent) of online tickets are sold on the day of the show, when there is little weather-uncertainty left. Between one and four days in advance, for which there is data on the weather forecast available, 30 percent of online tickets are sold, with percentages declining the earlier the tickets are purchased. The remaining 10 percent of online tickets are sold five or more days before the show. ${ }^{8}$

Our main variable of interest is aggregate ticket orders on a daily basis. More precisely, each

\footnotetext{
${ }^{6}$ There are in all 12 observations of the symbol overcast, which we group with "shower" to simplify the exposition of the results. Undoing this grouping does not lead to any significant changes throughout.

7 Online ticket prices have been stable at 5.70 Euro (about 7.85 Dollar) each over the entire period. This includes the regular ticket price of 5 Euro plus a 0.70 Euro service surcharge for buying online; the price is charged to the customer's credit card as soon as the order is completed. There is no further price discrimination with respect to when or where a ticket is bought. The only difference between online ticket holders and customers who buy tickets at the box office is that there may be, depending on demand for the movie night, a separate line for online ticket holders to pick up their tickets (all tickets need to be purchased at the box office or picked up at the call window, which are both located at the entrance of the theater). All tickets allow entry into the theater. There is no assigned seating and none of the seats are covered. See Figure 10 in Appendix E for a picture of the theater.

${ }^{8}$ We observe customers who do not buy their tickets online only in a survey which we conducted at the cinema in 2011 (see the next subsection). In Appendix D, we list all questions asked in this survey and present summary statistics of the customers' answers separately for online and offline customers. Based on these statistics, both groups of customers appear to be very similar.
} 
Table 2: Summary Statistics: Ticket Orders

\begin{tabular}{lccccc}
\hline & Day of Show & 1 Day in Advance & 2 Days in Adv. & 3 Days in Adv. & 4 Days in Adv. \\
\hline Avg. Daily Orders & 24.74 & 7.18 & 2.78 & 1.36 & 0.89 \\
& $(33.97)$ & $(10.82)$ & $(4.30)$ & $(2.24)$ & $(1.37)$ \\
Tickets per Order & 2.46 & 2.55 & 2.55 & 2.63 & 2.58 \\
& $(0.69)$ & $(0.92)$ & $(0.88)$ & $(1.24)$ & $(1.24)$ \\
\hline
\end{tabular}

Notes: We report means and standard deviations (in parentheses) of daily ticket orders and of the number of tickets per order for all orders between the day of the movie and four days in advance.

observation is the sum of ticket orders on a single day for a specific show. If no tickets are sold on a day at most four weeks before the movie night, we add an observation with aggregate orders of zero. This results in at least 29 observations for every single movie shown, one for each day between 0 and 28 days in advance. The summary statistics for ticket orders are presented in Table 2 , organized according to how far in advance the ticket was sold. The average number of ticket orders decreases from 7 one day in advance to 1 four days in advance, representing a declining pattern of orders. The number of tickets sold per order remains stable at about 2.6, independent of the time horizon. About half of the ticket orders are placed by repeat customers, who have bought tickets online more than once.

For 2009-2011, we additionally know for each order whether customers used their tickets or whether the ticket expired. Of the total of 4,102 online orders in those years, the vast majority ( 88 percent) were used.

\subsection{Survey}

During the 2011 season, we conducted a survey among visitors of the cinema. We will use the results from the survey to provide supporting evidence for our arguments. Overall we received 443 questionnaires at 13 different days with considerable variance in weather conditions (and accordingly varying number of questionnaires obtained per day). This amounts to more than 10 percent of the audience on these days on average. The purchasing behavior of the surveyed customers matches the overall purchasing behavior very well: 25 percent of surveyed customers bought their tickets online (compared to 24 percent of all customers 2009-2011) and 7 percent purchased them between one and four days in advance (compared to 8 percent of all customers). Appendix D lists the questions asked and presents summary statistics of the visitors' answers.

\section{Weather Effects on Ticket Orders}

In this section, we first provide a simple graphical illustration of our main argument. We then discuss our identification strategy and show econometrically that variation in purchase-date weather explains variation in advance ticket orders for all purchase horizons as well as for short-run (within day) weather fluctuations. 
Figure 1: Ticket Orders and Movie-Date Weather / Movie Popularity

This figure plots the average of residuals of log online ticket orders (termed "atypical ticket orders" in the text) on the day of the movie night for each decile of residual movie-date sunshine duration (panel (a), termed "atypical sunshine duration" in the text) and for each decile of a movie's popularity measured by gross ticket sales (for indoor theaters) on its opening weekend in Germany (panel (b)). Residuals are the values of the respective variable net of their movie-date and purchase-horizon specific conditional means.

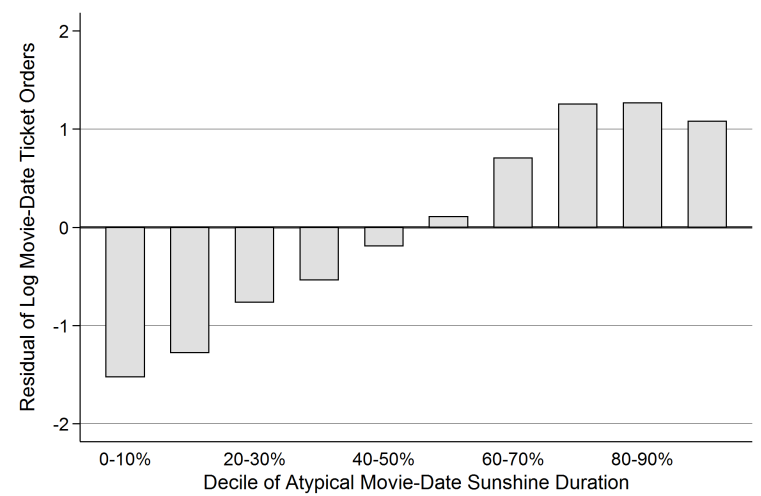

(a) Same-Day Ticket Orders by Movie-Date Sunshine Duration

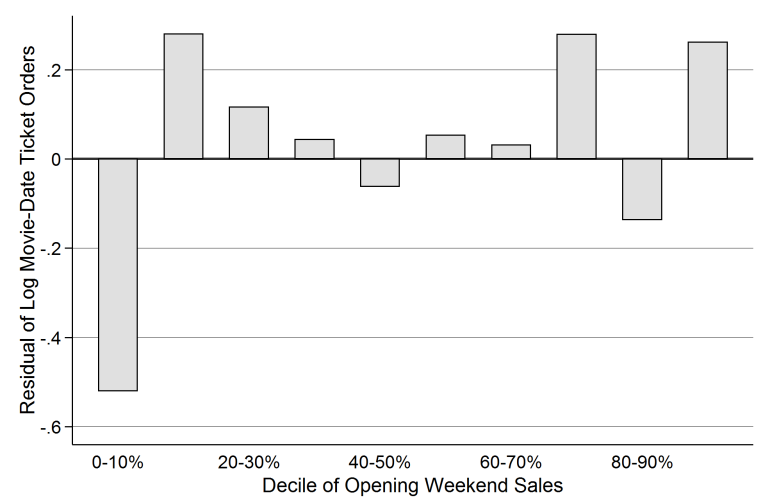

(b) Same-Day Ticket Orders by Movie Popularity

\subsection{Illustrative Evidence}

We first present evidence that movie-date weather and movie-date ticket orders are strongly correlated. Because little uncertainty regarding the weather for the movie night is left on the day of the movie, the strong correlation between realized movie-date weather and ticket orders shortly before the movie indicates that good weather prompts many potential customers to buy tickets and hence suggests that for the majority of customers the weather needs to be sufficiently good to enjoy watching a movie outdoors.

Our main identification strategy (outlined in Section 3.2) uses atypical weather to explain atypical ticket orders. We will mimic this strategy in the following graphical illustrations. For ticket orders, we use the transformation $\ln$ (orders +1 ) to account for the count-data characteristics of aggregate daily orders (non-linearity of orders over time, many observations equal to zero). Atypical ticket orders are defined by the deviation of $\ln$ (orders +1 ) from its movie-date and purchase-horizon specific mean for all purchase dates up to four weeks prior to the day of the movie. Atypical weather is constructed accordingly. ${ }^{9}$

Panel (a) of Figure 1 displays the average of atypical same-day ticket orders by decile of atypical movie-date sunshine duration. ${ }^{10}$ It becomes apparent that both variables exhibit a strong positive

\footnotetext{
${ }^{9}$ Formally, atypical ticket orders and atypical weather are the residuals of a regression of $\ln ($ orders +1$)$ or the relevant weather variable on dummies for the purchase horizon (measured in days ahead of the day of the movie) and movie-date fixed effects for purchase horizons between the day of the movie and the date 28 days prior to the day of the movie. The goal of taking the logarithm of ticket orders is to transform the exponential Poisson regression model (used in the econometric analyses below) into a linear form in order to enable the standard interpretation of atypical ticket orders as the deviation from a conditional mean.

${ }^{10}$ In Appendix A, we repeat the analysis presented here with rainfall as the relevant weather dimension.
} 
correlation. In the highest deciles of atypical sunshine duration, ticket orders are on average about $2.5 \mathrm{log}$ points higher than in the lowest deciles, corresponding to a difference in ticket orders of more than two times the mean. ${ }^{11}$ Note, moreover, that atypical ticket orders are positive, once atypical sunshine duration is above its median. To put this result in perspective, Panel (b) of Figure 1 shows average atypical same-day ticket orders by decile of the movie's gross ticket (indoor) sales on its opening weekend in Germany. Interpreting the initial gross ticket sales as an indicator of the popularity of the movie, there is at best little correlation between same-day ticket sales and the movie's popularity. Hence, it seems that good weather motivates customers significantly more to buy tickets on the day of the movie than the movie's popularity, suggesting customers' experienced utility varies heavily with realized weather during the movie. ${ }^{12}$

Given that movie-date weather is a seemingly important determinant of the experienced utility, we expect that customers carefully use available information (e.g., from weather forecasts) to predict future weather when they consider buying tickets in advance. This would imply a relation between movie-date weather and advance ticket orders. The four panels of Figure 2 plot average atypical ticket orders between one and four days ahead of the day of the movie by deciles of atypical moviedate sunshine duration. As expected, there is a positive correlation between advance orders and movie-date weather, at least up to two days prior to the day of the movie. The correlation seems to become weaker three days ahead, and more or less ceases to exist four days ahead, reflecting, perhaps, the decreasing reliability of weather forecasts.

The correlations presented so far show that customers make their purchasing decisions conditional on (expected) movie-date weather, consistent with the standard model of (expected) utility maximizing individuals. Yet, several psychological models of behavior predict that individual decisions under uncertainty are also affected by the state of the world at the time of the decision, in our case purchase-date weather. To illustrate this possibility, Figure 3 shows the average of atypical ticket orders between one and four days ahead of the day of the movie, but this time by decile of purchase-date atypical sunshine duration. For ticket orders one and two days in advance, the correlation of (current) purchase-date weather and advance sales is similar in magnitude to the correlation of (future) movie-date weather and ticket orders. However, while the correlation between movie-date weather and orders starts to break down three days in advance and earlier, the correlation of purchase-date weather and sales remains fairly stable. Moreover, note that atypical purchase-date sunshine duration above the median is associated with positive atypical advance ticket orders, while atypical weather below its median is associated with negative atypical orders.

This substantial correlation between current weather and advance ticket orders potentially implies that intertemporal biases play an important role in explaining the behavior of customers. Before

\footnotetext{
${ }^{11}$ In the lowest two deciles, the sun is shining on average 7 percent of the time, while in the highest two deciles, the sun is shining 92 percent of the time.

${ }^{12}$ It is unlikely that finding no correlation between ticket orders and movie popularity is due to insufficient variation, as the coefficient of variation of opening weekend gross sales equals 1.5 and is thus relatively large. Note, however, that we partial out movie-date fixed effects and hence control for the movie's effect on total online orders. Yet, in the previous version of this paper we also find no correlation between gross sales and same-day ticket orders in unadjusted data.
} 
Figure 2: Movie-Date Sunshine Duration and Advance Ticket Orders

This figure plots the average of residuals of log ticket orders (termed "atypical ticket orders" in the text), separately for orders one to four days in advance, for each decile of residual movie-date sunshine duration (termed "atypical sunshine duration" in the text). See the notes of Figure 1 for the definitions of the variables.

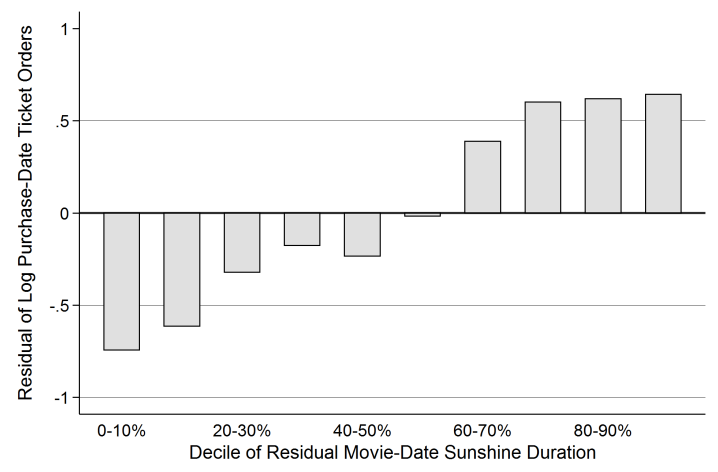

(a) Ticket Orders One Day Ahead

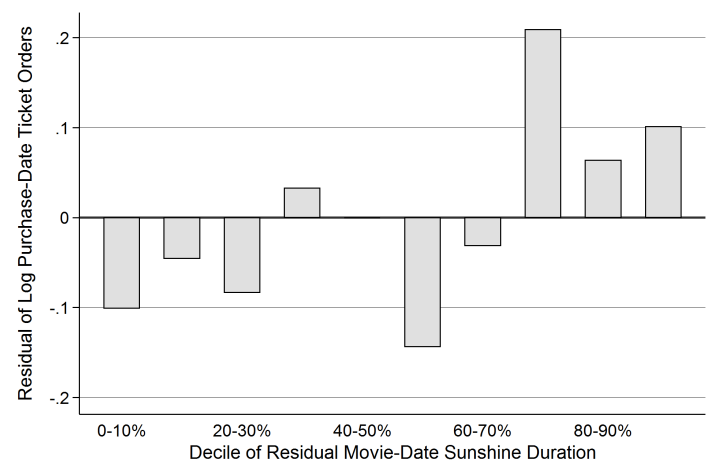

(c) Ticket Orders Three Days Ahead

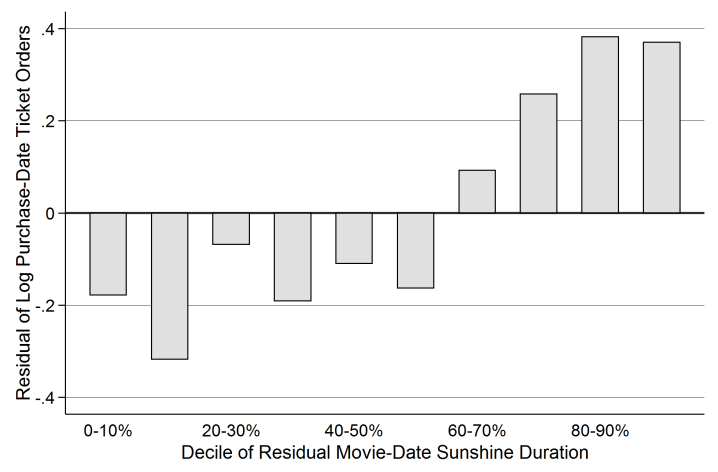

(b) Ticket Orders Two Days Ahead

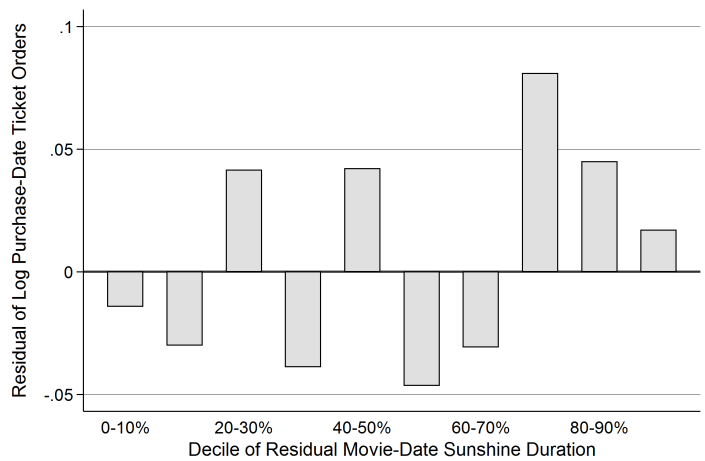

(d) Ticket Orders Four Days Ahead

we discuss potential explanations for this correlation, however, we first establish its presence by more formal empirical analyses.

\subsection{Identification Strategy and Empirical Model}

The following data generating process governs our choice of empirical models. At date $t$, potential customers who actively consider purchasing a ticket for the movie night at $\tau>t$ are assumed to arrive at a specified rate. Each of these customers then orders a ticket with a specific probability. We assume that both the arrival rate of the customers as well as the probability of ordering tickets are functions of purchase-date weather, expected movie-date weather (as predicted, for example, by the weather forecast), the purchase horizon $\tau-t$, as well as fixed movie characteristics. Ticket orders follow a Poisson process if, conditional on these variables, the arrival rate of potential customers is memoryless; under this assumption, expected ticket orders $y_{t \tau}$ are given by the product of the arrival rate and the purchasing probability.

We use count regressions to estimate the effect of the current weather (and other covariates) on 
Figure 3: Purchase-Date Sunshine Duration and Advance Ticket Orders

This figure plots the average of residuals of log ticket orders (termed "atypical ticket orders" in the text), separately for orders one to four days in advance, for each decile of residual purchase-date sunshine duration (termed "atypical sunshine duration" in the text). See the notes of Figure 1 for the definitions of the variables.

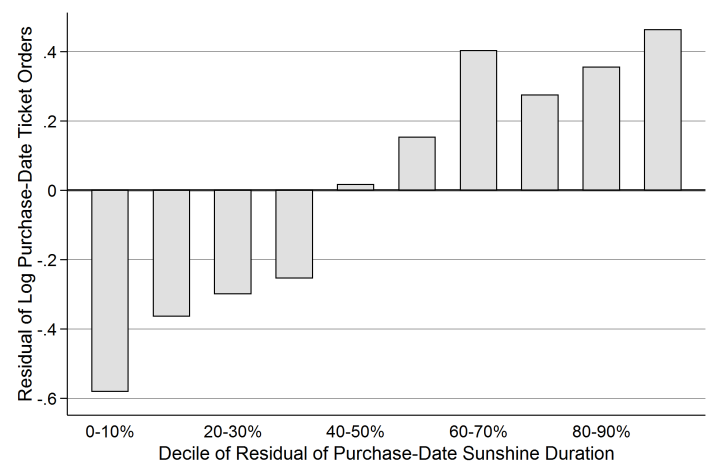

(a) Ticket Orders One Day Ahead

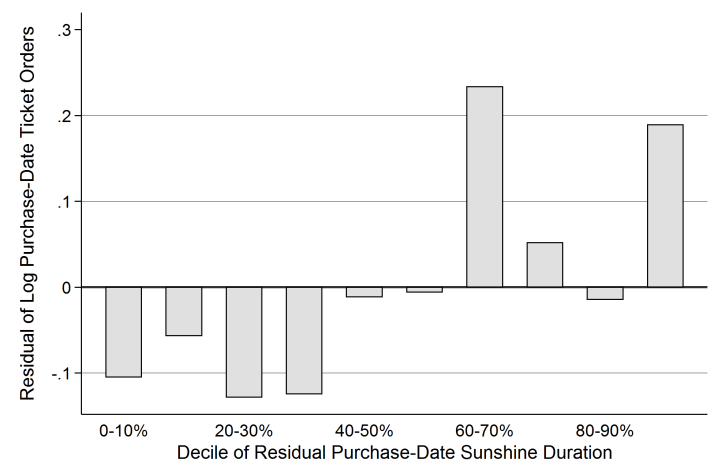

(c) Ticket Orders Three Days Ahead

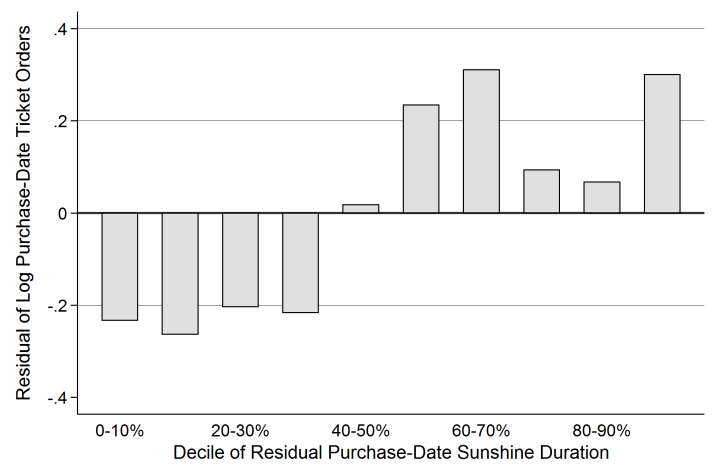

(b) Ticket Orders Two Days Ahead

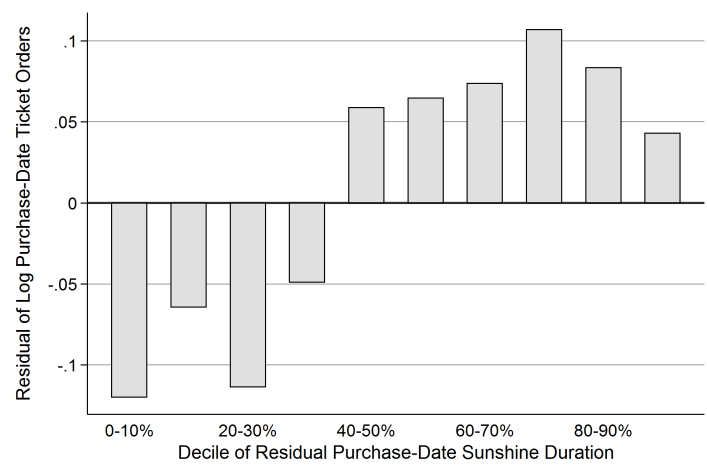

(d) Ticket Orders Four Days Ahead

ticket orders. ${ }^{13}$ This means that the conditional mean of advance ticket orders $y_{t \tau}$ is modeled by the (piecewise) exponential function

$$
y_{t \tau}=\exp \left(\text { Weather }_{\mathbf{t}}^{\prime} \boldsymbol{\beta}_{\boldsymbol{W}}+\text { Forecast }_{\boldsymbol{t} \tau}{ }^{\prime} \boldsymbol{\beta}_{\boldsymbol{F}}+\mu_{\tau}+\delta_{t \tau}\right)
$$

Weather $_{\mathbf{t}}$ is a vector including purchase-date average sunshine duration and average hourly rainfall, as well as their two-week moving averages to control for recent weather trends. The vector Forecast $_{\boldsymbol{t} \tau}$ controls for expected movie-date weather by either the forecast as of date $t$ of the weather for date $\tau$ (maximum and minimum forecast temperatures; dummy variables for each forecast symbol) or by a proxy for the expected weather given by the interaction of realized movie-date weather (average sunshine duration and rainfall) and dummies for the purchase horizon $\tau-t$. In addition to the weather and forecast variables, (1) includes purchase-horizon fixed effects $\delta_{t \tau}$, which control for the time-trend of advance orders: orders tend to increase for days of purchase closer to

\footnotetext{
${ }^{13}$ Under more restrictive assumptions, the hazard rate of ticket orders among potential customers can be identified and estimated via event history analysis. See Appendix B.1 for details.
} 
the day of the movie. We also control for movie-date fixed effects $\mu_{\tau}$, which absorb fixed moviedate characteristics. As a consequence, we identify the effect of the weather on ticket orders from variations in weather over the purchase horizon for a given movie (e.g., the change in the weather between three and two days before the movie). ${ }^{14}$

There are various empirical models to estimate the conditional mean (1). We follow the standard approach and use Poisson panel regressions for the estimations. ${ }^{15}$

\subsection{Empirical Results}

Table 3 shows the parameter estimates of model (1). The main parameters of interest are the elements of $\beta_{\mathbf{F}}$, that is, the coefficients of purchase-date average sunshine duration (measured as a fraction of an hour) and average rainfall per hour (measured in millimeters). Due to the properties of Poisson regressions, these parameters can be interpreted as the percentage increase in ticket orders due to a one-unit change in the corresponding weather variable.

Despite being irrelevant for enjoying the movie night and similar to the graphical analysis in Figure 3, the estimates show that purchase-date weather - in particular sunshine duration - affects ticket orders in an economically and statistically significant way. The estimates imply that ticket orders on a completely sunny day are 50 percent higher than when it is completely cloudy. Similarly, for each additional millimeter of rainfall per hour, ticket orders decrease by about 20 percent on average. These magnitudes are fairly constant across specifications. In Columns 1 and 2, we consider only ticket orders between one and four days in advance, which is the interval for which the weather forecast for the day of the movie is available. In Column 1, we control for expected moviedate weather via variables of the weather forecast. In Column 2, the expected weather is proxied by realized movie-date weather interacted with dummies for the purchase horizon. Mirroring the graphical analyses in Figure 2, expected movie-date weather only affects purchase-date ticket orders one and two days in advance, which are the purchase horizons for which the forecast is the most accurate.

In Columns 3 and 4 we repeat the analysis for purchase horizons up to four weeks in advance. ${ }^{16}$ The estimated parameters of purchase-date weather are hardly affected, with the notable exception that the parameter of rainfall becomes statistically significant. This is possibly due to an increase in the within movie-date variation in average daily rainfall, for which many observations are zero

\footnotetext{
${ }^{14}$ Note that using the time variation in covariates for identification is non-standard here, due to the inherent variation of ticket orders over purchase horizons (i.e., a non-stationarity of ticket orders). As a consequence, the weather and horizon effects may interact. In Appendix B.2 we describe and estimate an empirical model that uses the "cross-sectional" variation in weather across ticket orders with a fixed purchase horizon. These estimates are robust to a potential interaction of the horizon and weather effects, and are very similar to the ones identified using model (1).

15 Poisson regressions may be inadequate if the data has overdispersion, that is, a conditional variance of ticket orders larger than the conditional mean $y_{t \tau}$. However, we reject the hypothesis of overdispersion when estimating (1) via the NB2 model, possibly due to controlling for heterogeneity via fixed effects (see Cameron and Trivedi, 1998).

${ }^{16}$ In Column 3, in which we control for expected movie-date weather via the weather forecast, we set the forecast variables to zero for all observations 5 days in advance or earlier.
} 
Table 3: The Effect of Purchase-Date Weather on Ticket Orders

\begin{tabular}{|c|c|c|c|c|}
\hline & \multicolumn{4}{|c|}{ Daily Ticket Orders } \\
\hline & \multicolumn{2}{|c|}{ 1-4 Days Ahead } & \multicolumn{2}{|c|}{ 1-28 Days Ahead } \\
\hline & (1) & $(2)$ & $(3)$ & $(4)$ \\
\hline \multirow[t]{2}{*}{ Avg. Sunshine Duration } & $0.52^{* * *}$ & $0.46^{* * *}$ & $0.48^{* * *}$ & $0.47^{* * *}$ \\
\hline & $(0.11)$ & $(0.10)$ & $(0.08)$ & $(0.07)$ \\
\hline \multirow[t]{2}{*}{ Avg. Rainfall per Hour } & -0.27 & -0.15 & $-0.18^{*}$ & $-0.19^{*}$ \\
\hline & $(0.18)$ & $(0.16)$ & $(0.09)$ & $(0.11)$ \\
\hline \multirow[t]{2}{*}{ Avg. Sunshine Past 14 Days } & 0.02 & -0.67 & $1.46^{* * *}$ & $1.51^{* * *}$ \\
\hline & $(0.88)$ & $(0.89)$ & $(0.46)$ & $(0.58)$ \\
\hline \multirow[t]{2}{*}{ Avg. Rainfall Past 14 Days } & -1.86 & -1.77 & $-1.44^{* *}$ & $-1.46^{* * *}$ \\
\hline & $(1.56)$ & $(1.54)$ & $(0.63)$ & $(0.55)$ \\
\hline \multirow{2}{*}{ Forecast Maxtemp. } & 0.02 & & $0.10^{* * *}$ & \\
\hline & $(0.02)$ & & $(0.02)$ & \\
\hline \multirow[t]{2}{*}{ Forecast Mintemp. } & -0.02 & & -0.02 & \\
\hline & $(0.02)$ & & $(0.02)$ & \\
\hline \multirow[t]{2}{*}{ Symbol Partly Sunny } & 0.05 & & $-0.22^{* *}$ & \\
\hline & $(0.07)$ & & $(0.10)$ & \\
\hline \multirow[t]{2}{*}{ Symbol T-Storm } & -0.11 & & $-0.63^{* * *}$ & \\
\hline & $(0.09)$ & & $(0.12)$ & \\
\hline \multirow[t]{2}{*}{ Symbol Shower } & 0.01 & & $-0.49^{* * *}$ & \\
\hline & $(0.13)$ & & $(0.14)$ & \\
\hline \multirow[t]{2}{*}{ Symbol Rain } & -0.50 & & $-1.36^{* * *}$ & \\
\hline & $(0.49)$ & & $(0.42)$ & \\
\hline \multirow{2}{*}{1 Day Ahead × Movie-Date Sunshine } & & $0.97^{* * *}$ & & $1.03^{*}$ \\
\hline & & $(0.25)$ & & $(0.62)$ \\
\hline \multirow[t]{2}{*}{1 Day Ahead $\times$ Movie-Date Rainfall } & & $-1.26^{* * *}$ & & $-1.66^{* *}$ \\
\hline & & $(0.31)$ & & $(0.68)$ \\
\hline \multirow[t]{2}{*}{2 Days Ahead $\times$ Movie-Date Sunshine } & & $0.51^{* *}$ & & 0.57 \\
\hline & & $(0.23)$ & & $(0.61)$ \\
\hline \multirow[t]{2}{*}{2 Days Ahead $\times$ Movie-Date Rainfall } & & $-0.48^{* *}$ & & -0.82 \\
\hline & & $(0.23)$ & & $(0.69)$ \\
\hline \multirow[t]{2}{*}{3 Days Ahead $\times$ Movie-Date Sunshine } & & 0.05 & & 0.13 \\
\hline & & $(0.24)$ & & $(0.61)$ \\
\hline \multirow{2}{*}{3 Days Ahead $\times$ Movie-Date Rainfall } & & -0.26 & & -0.55 \\
\hline & & $(0.29)$ & & $(0.72)$ \\
\hline Horizon FEs & yes & yes & yes & yes \\
\hline \multicolumn{5}{|l|}{ Horizon $\times$ Movie-Date Weather } \\
\hline for more than 3 Days Ahead & no & no & no & yes \\
\hline Movie-Date FEs & yes & yes & yes & yes \\
\hline Observations & 1353 & 1710 & 12383 & 12790 \\
\hline
\end{tabular}

Notes: We report the coefficients and standard errors (clustered on the movie-date level) from Poisson panel regressions of daily ticket orders on purchase-date weather conditions (average sunshine duration as a fraction of an hour, average hourly rainfall in $\mathrm{mm}$, and their 14-day moving averages), variables describing expected movie-date weather at the time of purchase, purchase-horizon fixed effects, and movie-date fixed effects. See the empirical model (1) for details. Columns 1 and 2 restrict the data to ticket orders between one and four days ahead of the day of the movie, Columns 3 and 4 estimate (1) for orders up to four weeks in advance. In Columns 1 and 3 we control for expected weather using the variables of the weather forecast (maximum and minimum temperatures in degree Celsius, mutually exclusive forecast indicators); the omitted forecast category is "sunny." These variables are set to zero for purchase horizons earlier than four days, for which data on forecasts for the day of the movie is unavailable. In the remaining columns, we proxy for expected movie-date weather by interactions of realized movie-date weather and dummies for the purchase horizon. Level of significance: ${ }^{*} p<0.10,{ }^{*} p<0.05,{ }^{* * *} p<0.01$. 
Table 4: The Effect of Purchase-Date Weather on Early Ticket Orders

\begin{tabular}{lccc}
\hline & \multicolumn{3}{c}{ Daily Ticket Orders } \\
\cline { 2 - 4 } & $7-28$ Days Ahead & $14-28$ Days Ahead & $21-28$ Days Ahead \\
\hline Avg. Sunshine Duration & $0.42^{* * *}$ & $0.33^{* *}$ & $0.49^{* *}$ \\
& $(0.09)$ & $(0.15)$ & $(0.24)$ \\
Avg. Rainfall per Hour & -0.02 & 0.11 & 0.12 \\
& $(0.12)$ & $(0.20)$ & $(0.27)$ \\
Avg. Sunshine Past 14 Days & $1.14^{* *}$ & 1.09 & $(1.23)$ \\
& $(0.45)$ & $(0.80)$ & -3.29 \\
Avg. Rainfall Past 14 Days & $-2.06^{* * *}$ & $-3.08^{* *}$ & $(2.79)$ \\
& $(0.79)$ & $(1.42)$ & yes \\
& yes & yes & yes \\
Horizon FEs & yes & yes & yes \\
Horizon $\times$ Movie-Date Weather & yes & yes & 973 \\
Movie-Date FEs & 7579 & 3503 & .
\end{tabular}

Notes: We report, for different purchase-horizons, the coefficients and standard errors (clustered on the movie-date level) from Poisson panel regressions of daily ticket orders on purchase-date weather conditions (average sunshine duration as a fraction of an hour, average hourly rainfall in $\mathrm{mm}$, and their 14-day moving averages), purchase-horizon fixed effects, and movie-date fixed effects. Interactions of realized movie-date weather and dummies for the purchase horizon are used to proxy for expected movie-date weather. Level of significance: $* p<0.10, * * p<0.05, * * * p<0.01$.

valued. In addition, good recent weather, as measured by 14-day moving averages of prior sunshine duration and rainfall, seems to exert a positive impact on ticket orders. ${ }^{17}$

One possible concern regarding the results in Table 3 could be that they are exclusively driven by ticket orders on days close to the day of the movie, when the current weather may be perceived to have predictive power for movie-date weather (which is not the case, as we will demonstrate in Section 4.1). For this reason, we estimate the effect of the current weather on ticket orders earlier than one, two, or three weeks before the movie. The results in Table 4 show that good purchase-date weather is associated with an increase in orders independently of the particular purchase-horizon. Moreover, the size of the effect of the weather on sales seems to be fairly constant over time, as the estimated coefficients of sunshine duration for early orders take on similar values as the coefficients for the entire purchase horizon in Table 3.

If it is indeed the current weather (as opposed to recent weather) that causes advance ticket orders, we would expect to find orders affected not only by daily variation in the weather, but also by weather changes within a day, e.g., from one hour to the next. To test this conjecture, we disaggregate daily ticket orders by hour and use the hourly ticket orders as the dependent variable in a variant of model (1), in which we include hourly measures of weather (sunshine duration and rainfall) as well as hour-of-day fixed effects as additional independent variables. In addition, we restrict the sample to hours with potentially positive sunshine duration ( 8 am to $8 \mathrm{pm})$ as well as to hours in the morning ( 8 am to $2 \mathrm{pm}$ ) and afternoon ( $2 \mathrm{pm}$ to $8 \mathrm{pm}$ ) for days of purchase between one and four days ahead of the movie. In this empirical model, the effect of the hourly weather on ticket

\footnotetext{
${ }^{17}$ In Columns 1 and 2 of Table 12 in Appendix $E$ we show that the effect of weather on ticket orders is independent of the movie's genre, the day of the week of its showing, and day of the week of the purchase.
} 
Table 5: The Effect of Hourly Weather on Ticket Orders per Hour

\begin{tabular}{lccc}
\hline & Hourly Ticket Orders $(1-4$ Days Ahead $)$ \\
\cline { 2 - 4 } & Daytime & Morning & Afternoon \\
& $(1)$ & $(2)$ & $(3)$ \\
\hline Current Sunshine Duration & $0.16^{* *}$ & 0.16 & $0.20^{*}$ \\
Current Rainfall & $(0.07)$ & $(0.13)$ & $(0.11)$ \\
& -0.01 & -0.04 & -0.01 \\
Avg. Sunshine Duration & $(0.04)$ & $(0.10)$ & $(0.04)$ \\
& $0.36^{* * *}$ & $0.36^{*}$ & $0.32^{* *}$ \\
Avg. Rainfall per Hour & $(0.12)$ & $(0.21)$ & $(0.15)$ \\
& -0.22 & -0.26 & -0.18 \\
Avg. Sunshine Past 14 Days & $(0.17)$ & $(0.21)$ & $(0.23)$ \\
Avg. Rainfall Past 14 Days & -0.59 & -0.34 & -0.76 \\
& $(0.95)$ & $(1.41)$ & $(1.08)$ \\
& -2.36 & -0.80 & $-3.52^{* *}$ \\
\hline Horizon FEs & $(1.63)$ & $(2.64)$ & $(1.69)$ \\
Hour-of-Day Dummies & yes & yes & yes \\
Horizon $\times$ Movie-Date Weather & yes & yes & yes \\
Movie-Date FEs & yes & yes & yes \\
Observations & yes & yes & yes \\
\hline
\end{tabular}

Notes: We report the coefficients and standard errors (clustered on the movie-date level) from Poisson panel regressions of hourly ticket orders ( 1 to 4 days in advance) on current weather conditions (hourly sunshine duration as the fraction of the hour, hourly rainfall in $\mathrm{mm}$, as well as the daily averages and 14 day moving averages of these variables), purchase-horizon fixed effects, hour-of-day fixed effects, and movie-date fixed effects. Interactions of realized movie-date weather and dummies for the purchase-horizon are used to proxy for expected movie-date weather. Column 1 reports coefficients for all orders between 8 am and $8 \mathrm{pm}$. In the two remaining columns we split the dataset into orders before and after $2 \mathrm{pm}$. Level of significance: ${ }^{*} p<0.10$, ** $p<0.05$, $^{* *} p<0.01$.

orders per hour is identified from the variation of the weather within a day, holding constant the average weather conditions on that day. ${ }^{18}$ Table 5 shows that the within-day variation in weather explains the hourly variation in ticket orders to a significant degree. If sunshine duration were to change from cloudy to sunny, hourly ticket orders would increase by 16 to 20 percent. The size of this effect is similar for morning and afternoon sales, but only the latter is statistically significant, which may be due to the higher variation in ticket orders during the afternoon hours, which is when most tickets are sold. ${ }^{19}$

\footnotetext{
${ }^{18}$ An alternative approach would be to regress hourly changes in ticket orders on hourly changes in weather. In count models, however, such a first-difference specification does not admit a closed form likelihood for any observation, as each possible difference can be generated by infinitely many combinations of Poisson arrivals across hours (i.e., a difference of 1 can be generated by orders of 0 and 1,1 and 2, and so on). In a previous version of this paper, we estimate a first difference model via OLS and find statistically significant effects of changes in weather on changes in sales.

${ }^{19}$ In Appendix B.1 we estimate the hourly hazard rate of ticket orders using event history models and find effects with similar sizes.
} 
Figure 4: Predictive Power of Current Sunshine Duration

This figure provides a scatterplot of the residuals of current sunshine duration against the residuals of future evening sunshine duration ( $5 \mathrm{pm}$ to $7 \mathrm{pm}, 1$ to 4 days into the future). Both residuals are relative to the respective year and month specific means. The black solid line depicts the linear regression of future on current sunshine residuals. The 95 percent confidence interval is given by the gray lines.

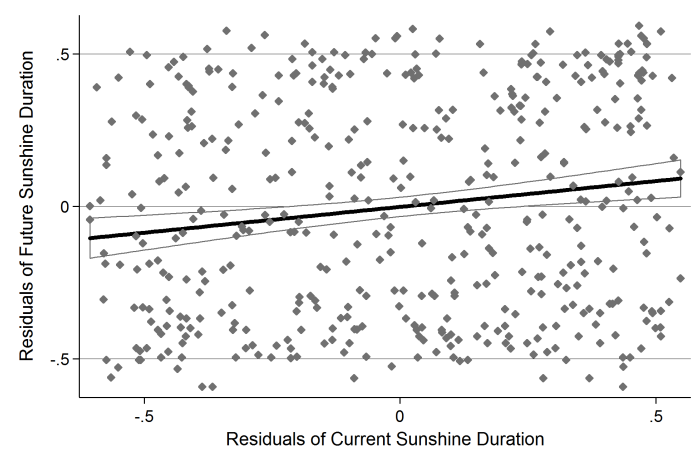

(a) 1 Day into the Future

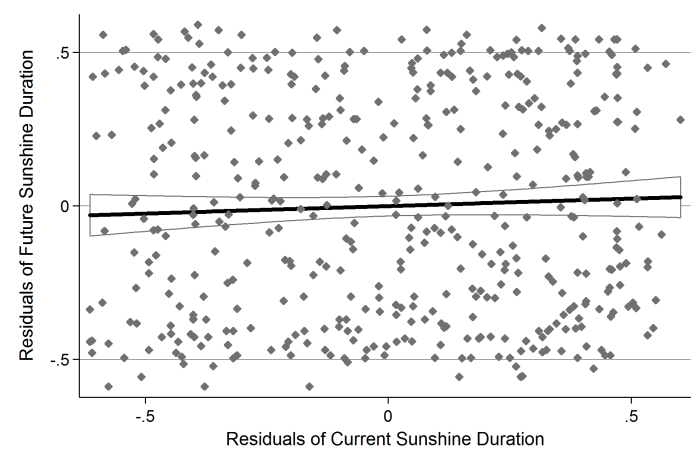

(c) 3 Days into the Future

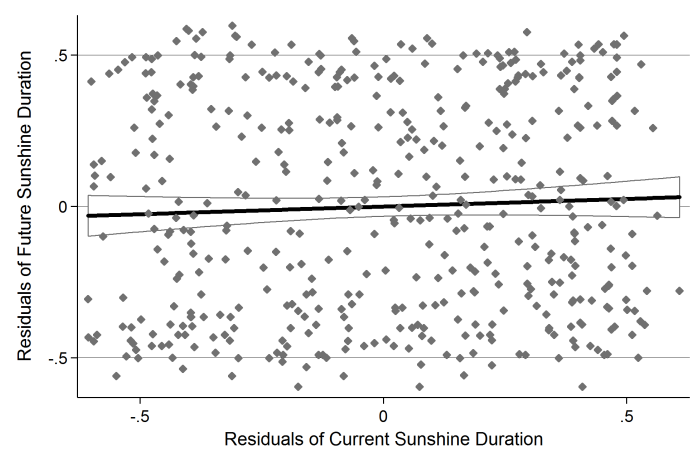

(b) 2 Days into the Future

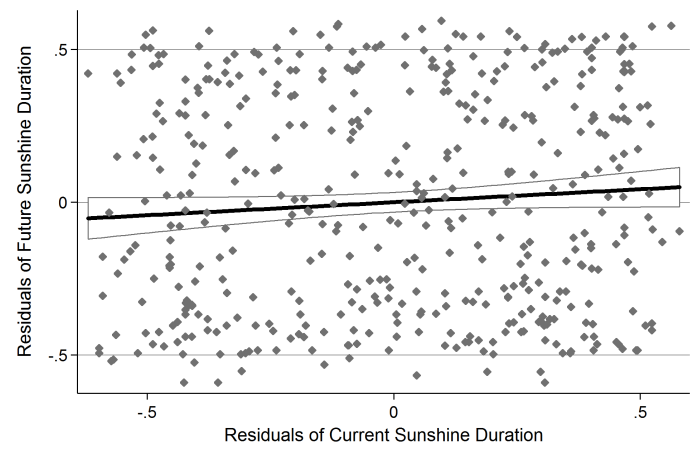

(d) 4 Days into the Future

\section{Rational Explanations for the Weather Effect}

In the previous section, we have shown that good weather on the day of purchase prompts the customers of the movie theater to buy advance tickets, even though purchase-date weather is irrelevant for enjoying a movie on a later date. In this section, we discuss whether there could be explanations for this weather effect apart from psychological mechanisms.

\subsection{Information Content of Current Weather for Future Weather}

An immediate concern for our analysis so far is that individuals use current weather to update their beliefs about future weather conditions. There are two reasons why this could be optimal. First, current weather may be informative in itself. so that consulting the weather forecast is unnecessary. Second, current weather may enhance the prediction of future weather, even given the weather forecast. This may be the case, for example, if the forecast cannot take regional factors into account sufficiently well. 
Figure 5: Predictive Power of Weather Forecasts

This figure provides a scatterplot of current forecast symbols against residuals of a regression of future evening sunshine duration ( $5 \mathrm{pm}$ to $7 \mathrm{pm}, 1$ to 4 days into the future) on month and year dummy variables. To visualize the variation within a forecast category, random noise is added to the observations. The black solid line connects the means of the residuals conditional on the forecast, the gray lines connect the 95 percent confidence intervals of the conditional means.

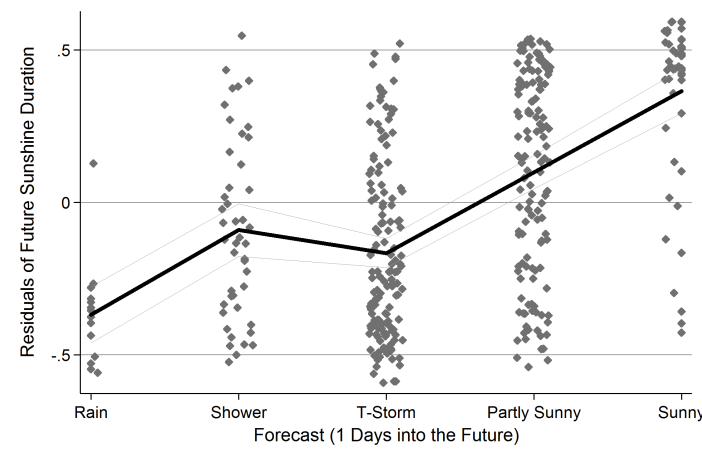

(a) 1 Day into the Future

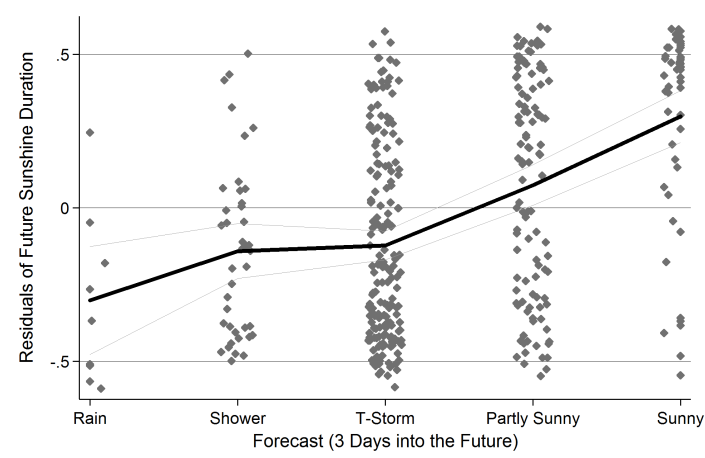

(c) 3 Days into the Future

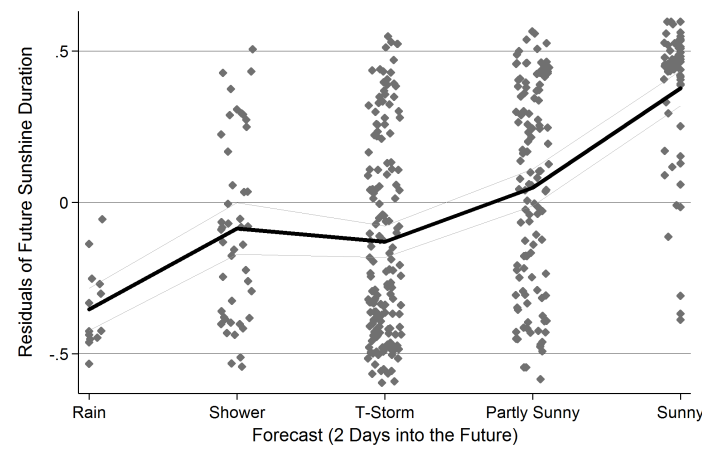

(b) 2 Days into the Future

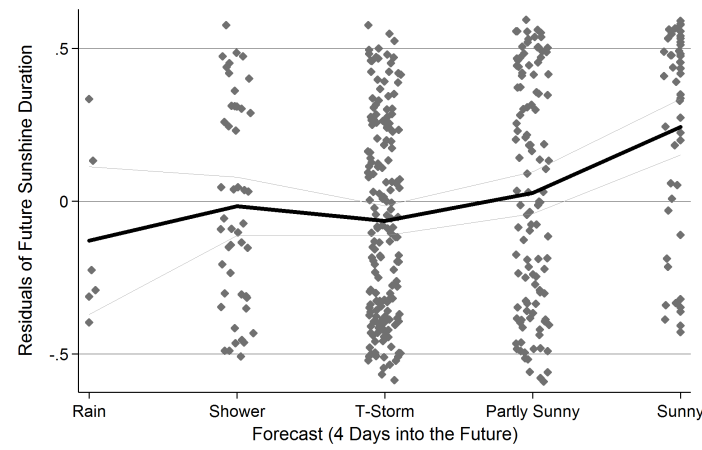

(d) 4 Days into the Future

We argue that the information content of the current weather for future weather is, in general, limited if not nil due to large day to day fluctuations of local weather in Munich. In Figure 4, we plot average evening sunshine duration one to four days ahead against current sunshine duration (both purged for seasonal effects by year and month dummies). It turns out that tomorrow's sunshine hours are at best slightly positively related to today's sunshine duration. Furthermore, today's weather has no explanatory power for weather two or more days into the future.

In contrast, the weather forecast is able to explain future sunshine duration well. Figure 5 plots average evening sunshine duration purged for seasonal effects as above, but this time against the forecast as given by forecast symbols. Evidently, there is a clear positive correlation between symbols indicating good future weather and realized sunshine duration.

In order to check that the predictive power of current weather, even when not controlling for the forecast, is low, we complement the graphical analysis above with empirical estimates. In particular, we forecast $S_{h}$, the evening sunshine duration $h$ days into the future, with the following model 


$$
\text { Sunshine }_{t h}=\text { Weather }_{\mathbf{t}}^{\prime} \gamma_{\boldsymbol{W}}+\text { Forecast }_{\mathbf{t h}}^{\prime} \gamma_{\boldsymbol{F}}+\mathbf{N}_{\mathbf{t}}^{\prime} \gamma_{\boldsymbol{N}}+\xi_{t h}
$$

where controls $\mathbf{N}_{\mathbf{t}}$ include year and month dummies. Current weather $\mathbf{W e a t h e r}_{\mathbf{t}}$ is defined as above and the forecast vector Forecast $_{\mathbf{t h}}$ includes all variables of the weather forecast of date $t$ for date $h$. We estimate model (2) for time horizons $h$ between one and four days, with and without including the forecast; the results are displayed in Table 13 in Appendix E. Confirming the graphical results, the current weather seems to be uninformative for future weather. The exception to this rule is column (1) in Table 13, where the coefficients of current sunshine duration are statistically significant but quantitatively small (a one percent increase in sunshine duration today leads to an increase in sunshine tomorrow of 0.12 percentage points on average). In contrast, the predictive power of the forecast is sizable: adding it to the model leads to a strong increase in variance explained. $^{20}$

Our results indicate that it cannot be optimal for customers to interpret the current weather as an informative signal for future weather. Hence, rational expectations cannot explain the previously found dependence of ticket orders on the current weather. Even if the vast majority of customers are locals and hence familiar with local weather patterns, we cannot rule out the possibility that customers perceive current weather to be informative. Yet, we have just shown that such perceptions would be at odds with the data, and should hence be attributed to a psychological rather than a rational mechanism. For this reason, we defer the discussion of this possibility to Section 5.3.

\subsection{Precautionary Ticket Orders and Purchase Timing}

Another concern is that due to capacity constraints higher ticket orders at any given point in time lead to a greater risk that the movie may sell out. In fact, this is not a relevant risk, as the theater in question is quite large (1,300 seats) and has been sold out only 13 percent of the time over the entire time span of our analysis. Over the entire analysis, however, it has never been sold out in advance, so that customers would always be able to buy tickets online until $6 \mathrm{pm}$ on the day of the screening (the latest date for buying tickets online). ${ }^{21}$

Nevertheless, customers may believe that the availability of tickets later on decreases with good current weather, which may lead to a weather dependent precautionary motive for buying tickets in advance. There may be two ways to support an equilibrium in which the precautionary motive may play a role. First, rational customers may expect that purchasing decisions of others are

\footnotetext{
${ }^{20}$ Survey results indicate that customers appreciate the predictive power of the weather forecast and consult the forecast frequently. From all respondents, 84 percent consult the weather forecast at least every other day or when they are planning weather related activities. Customers also appreciate the forecast's reliability: 85 (86) percent state that the forecast for tomorrow (two days ahead) will be correct at least 80 (60) percent of the time. See Appendix D for details.

${ }^{21}$ Survey results indicate that the main motivation for customers to buy tickets in advance is the worry that the theater may sell out (for 70 percent of advance customers), followed by the desire to avoid the line at the box office (23 percent of advance customers). This is despite the fact that 84 (74) percent of advance customers state that it is "unlikely" or "very unlikely" that tomorrow's screening will be sold out in advance (sold out at the box office shortly before the movie starts). See the answers to questions 6, 7 and 18 of the survey in Appendix D.
} 
Figure 6: Distributed Lag Analysis of Sunshine Duration and Rainfall

This figure shows the coefficient values and 95 percent confidence intervals of the effect of daily lags of average sunshine duration (Panel (a)) and daily lags of average rainfall (Panel (b)) on advance ticket orders. Coefficients are estimated with the same model underlying Column 4 of Table 3, except that the 14-day moving averages of the weather variables are replaced by 14 daily lags.

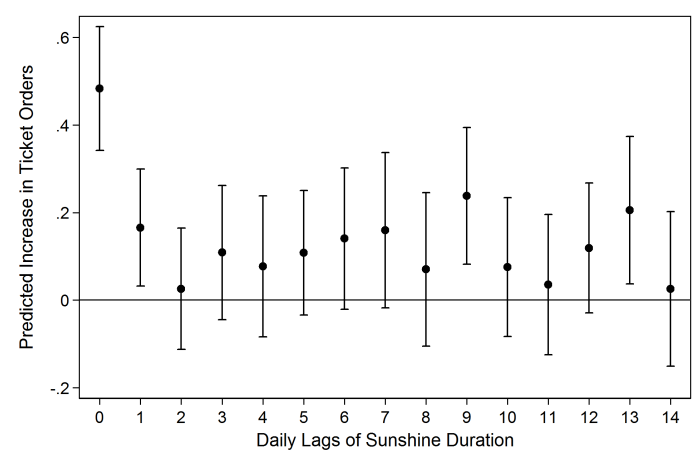

(a) 14 Lags of Sunshine Duration

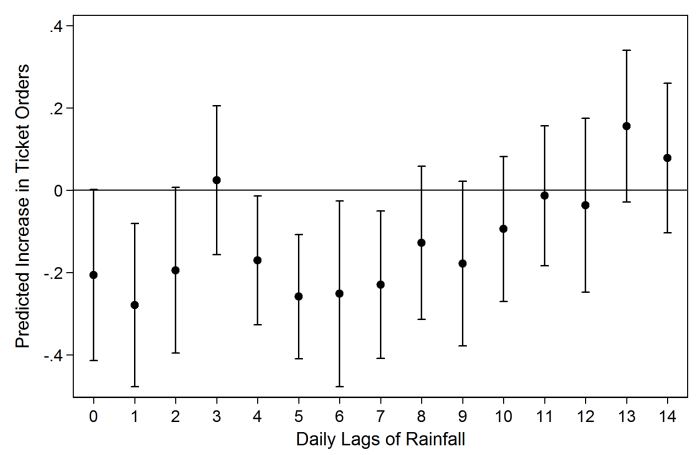

(b) 14 Lags of Rainfall

driven by psychological mechanisms. Then, the weather dependence of ticket orders would be caused by non-rational customers in the first place, but amplified by the precautionary motive of rational customers. Second, with only rational customers, the precautionary motive may prevail as an (inefficient) equilibrium of a coordination game. For this to be an equilibrium, the perceived increase in the risk that the theater sells out must cause exactly the boost in ticket orders underlying the increase in risk.

The first implication of the precautionary motive for purchase is that good weather causes rational customers to shift their purchasing decisions to an earlier date than originally planned. In other words, good weather leads to an intertemporal substitution of ticket orders from later to earlier dates. If the weather dependence of ticket orders were predominantly caused by precautionary motives, we would hence expect to find a decrease in today's orders if past weather was good.

In contrast to this prediction, the coefficients of the 14-day moving averages of sunshine duration and rainfall found in Tables 3 and 4 already suggest that past good weather is, if anything, positively associated with today's ticket orders. To further substantiate this finding, we estimate a distributedlag variant of our baseline empirical model (1) in which we replace the moving averages of past weather by 14 daily lags of sunshine duration and rainfall. ${ }^{22}$ Figure 6 plots the coefficients and 95 percent confidence intervals of current (daily lag equal to zero) and lagged sunshine duration and rainfall. The results show a large and significant positive effect of current sunshine duration (coefficient equal to 0.48) and a negative effect of current rainfall (coefficient equal to -0.20 ) on ticket orders; these are almost identical to the estimates of the main analysis in Table 3 . In addition, the coefficients of past sunshine duration are positive, but statistically insignificant most of the time. Past rainfall, in turn, has a negative effect on sales, at least for the past 10 days. Recall that these coefficients should have the opposite signs if the positive association between purchase-date weather

\footnotetext{
${ }^{22}$ See Busse et al. (2015) for a similar analysis.
} 
and ticket orders were caused by intertemporal substitution. We can hence dismiss the possibility that this is the sole mechanism driving our results.

A second implication of the precautionary motive for purchase is that potential customers should only consider rescheduling their purchase timing if good weather leads to a considerable increase in the risk that the theater sells out. At times, this may not be the case. For particularly early purchase horizons of one week or earlier, deferring the purchasing decision to a later date is riskless. Similarly, hourly variations in weather can be assumed to have little impact on the probability of ticket availability, as the hourly rate of ticket sales is low. The precautionary motive for ticket purchases is, hence, unable to explain the sizable effects of weather on early ticket orders or the increase in hourly sales caused by hourly improvements in weather shown in Tables 4 and 5 , respectively. We conclude that purchase-date weather does not affect ticket orders indirectly via market interactions that govern the probability of ticket availability. Rather, good weather seems to directly increase the number of ticket orders.

\subsection{Consumer Learning}

A third concern could be that the results are driven by inexperienced customers who have difficulty imagining their utility of watching a movie outdoors under different weather conditions. Such customers may try to infer their utility using current weather as an anchor, which could possibly lead to an overestimation of the expected utility at times of good weather. Before we discuss this hypothesis, we note that this mechanism already constitutes a misprediction of future utility linked

to current weather conditions. As such, it is closely related to the psychological mechanisms we discuss in Section 5.3. The distinction between misprediction due to inexperience and misprediction due to psychological mechanisms is that the former can be cognitively overcome by learning from experience, while it may be more difficult to learn about and overcome deeply rooted psychological biases.

The data contains the entire history of customers' online purchases (provided they always used the same account), so that there is information about their past experiences with visiting the theater. We use this information to study the purchase behavior of different subsets of experienced customers. To do so, we aggregate, for each combination of day of purchase and day of the movie, all ticket orders of four groups of repeat customers, and use these aggregates as the dependent variable in the empirical model (1). The subsets of customers considered are, first, all customers who are ordering their tickets at least the second time within the entire period from 2004 to 2011, second, customers who place at least the second order within any given summer, third, customers who experienced rainfall during a show they previously purchased tickets for, and fourth, customers who previously ordered a ticket on the day of the movie (which would be rational given the negligible risk of the theater's selling out: see Section 4.2).

Table 6 shows that the influence of purchase-date weather on ticket orders is fairly constant across all sets of customers. Ticket orders by the four subsets of experienced customers are between 42 and 59 percent higher on a completely sunny day than on a completely cloudy day, close and 
Table 6: Effect of Purchase-Date Weather on Ticket Orders of Repeat Customers

\begin{tabular}{|c|c|c|c|c|}
\hline \multirow[b]{2}{*}{ Repeat Customers Considered: } & \multicolumn{4}{|c|}{ Ticket Orders (1 - 28 Days Ahead) of Repeat Customers } \\
\hline & $\begin{array}{l}\text { All } \\
(1)\end{array}$ & $\begin{array}{c}\text { within Season } \\
(2)\end{array}$ & $\begin{array}{c}\text { Bad Experiences } \\
(3)\end{array}$ & $\begin{array}{c}\text { Movie-Date Order } \\
(4)\end{array}$ \\
\hline \multirow[t]{2}{*}{ Avg. Sunshine Duration } & $0.48^{* * *}$ & $0.51^{* * *}$ & $0.64^{* * *}$ & $0.50^{* * *}$ \\
\hline & $(0.10)$ & $(0.17)$ & $(0.17)$ & $(0.13)$ \\
\hline \multirow[t]{2}{*}{ Avg. Rainfall per Hour } & -0.24 & -0.04 & -0.21 & $-0.47^{*}$ \\
\hline & $(0.20)$ & $(0.26)$ & $(0.27)$ & $(0.27)$ \\
\hline \multirow[t]{2}{*}{ Avg. Sunshine Past 14 Days } & $1.27^{*}$ & $2.72^{* *}$ & 1.44 & 0.93 \\
\hline & $(0.68)$ & $(1.06)$ & $(0.93)$ & $(0.92)$ \\
\hline \multirow[t]{2}{*}{ Avg. Rainfall Past 14 Days } & $-2.07^{* * *}$ & -0.22 & $-2.17^{* *}$ & $-2.01^{* *}$ \\
\hline & $(0.78)$ & $(1.36)$ & $(1.03)$ & $(0.97)$ \\
\hline Horizon FEs & yes & yes & yes & yes \\
\hline Horizon $\times$ Movie-Date Weather & yes & yes & yes & yes \\
\hline Movie-Date FEs & yes & yes & yes & yes \\
\hline Observations & 11332 & 7845 & 7994 & 8782 \\
\hline
\end{tabular}

Notes: We report the coefficients and standard errors (clustered on the movie-date level) from Poisson panel regressions of (1). In each column, we use a different subsample of ticket orders to calculate daily ticket orders (the dependent variable). These criteria are related to customers' experiences with previous visits to the cinema. In the first (second) column, an order is only considered if it is not the customer's first order (not the first order in the current season). In the third and fourth columns, an order is only considered if the customer had previously ordered tickets for a movie-date at which there was rainfall during the night of the movie (Column 3 ) or if the customer has previously ordered tickets on the day of the movie (Column 4). The independent variables are as defined in Table 3. Level of significance: ${ }^{*} p<0.10,{ }^{* *} p<0.05, * * * x<0.01$.

statistically indistinguishable to the baseline estimate of 47 percent. Note, in particular, that purchasing decisions of customers with the unpleasant experience of rainfall during a previous visit are no less affected by current sunshine than are the decisions of all customers. Similarly, advance ticket orders of the most "rational" customers - those who had previously purchased tickets on the day of the show - are driven by purchase-date weather. Overall, these results strongly indicate that the weather dependence of purchasing decisions cannot be overcome by learning.

\section{Psychological Mechanisms}

So far, we have shown that good purchase-date weather increases ticket sales for the outdoor cinema and that it is difficult to reconcile this finding with rational behavior. In this section, we turn to candidate psychological theories that predict a relation between ticket orders and weather conditions on the day of purchase. Specifically, we will focus on the reminder effect of weather, projection bias, and extrapolative expectations, as well as the salience of choice alternatives as psychological mechanisms that may be able to explain the empirical evidence. Before we discuss each of these mechanisms in turn, however, we ask whether customers are more likely to erroneously purchase tickets at times of beautiful weather than at times of unpleasant weather in the sense that they let their tickets expire with higher probability. The answer to this question is not indicative for a specific mechanism to be at work. Nevertheless, we would expect that customers who are triggered 
to purchase tickets by some psychological bias have a higher rate of ex post mistakes than rational customers.

\subsection{Do Customers Erroneously Buy Tickets when the Weather is Nice?}

Customers may ex post decide that purchasing tickets was a mistake and that, on the day of the movie, they are better off letting their tickets expire. Conlin et al. (2007) propose to use such ex post mistakes to test for the presence of psychological biases. Specifically, they argue that customers who overestimate their future utility derived from a product are more likely to find, ex post, that their purchase has been a mistake. In our setting, the overestimation of future utility at times of good weather is only one potential psychological mechanism that could be consistent with both higher ticket orders and a higher rate of errors. Another explanation for both findings could be that good weather reminds customersto buy tickets, and that the marginal customer on days with nice weather is more sensitive to changes in weather than the marginal customer at times of bad weather. We return to these potential explanations in the following sections.

We estimate the probability that customers let their tickets expire using the Probit model

$$
\begin{aligned}
\operatorname{Pr}(\text { tickets expire })_{t \tau}=\Phi\left(\text { Weather }_{\mathbf{t}}^{\prime} \boldsymbol{\beta}_{\boldsymbol{W}}+\right.\text { Movie-Date } & \text { Weather }_{\tau}{ }^{\prime} \boldsymbol{\beta}_{\boldsymbol{M W}} \\
& \left.+ \text { Forecast }_{\mathbf{t} \tau}^{\prime} \boldsymbol{\beta}_{\boldsymbol{F}}+\boldsymbol{M}_{\boldsymbol{\tau}} \boldsymbol{\beta}_{\boldsymbol{M}}+\delta_{t \tau}\right)
\end{aligned}
$$

where $\Phi(\cdot)$ is the normal cdf. Our goal is to test whether good purchase-date weather at $t$, as measured by the usual vector $\mathbf{W e a t h e r}_{\mathbf{t}}$, causes customers to let their tickets expire more frequently at $\tau$. In addition, we control for the weather during or shortly before the movie summarized by the vector Movie-Date $\mathbf{W e a t h e r}_{\tau}$ (including the duration of evening sunshine as well as the temperature and rainfall during the movie), the weather forecast at the time of purchase, horizon fixed effects $\delta_{t \tau}$, and movie-date characteristics $\boldsymbol{M}_{\boldsymbol{\tau}}$ (year, month, and day-of-week fixed effects).

The first column of Table 7 shows that a longer sunshine duration and less rainfall on the day of purchase are both associated with a higher likelihood that the tickets will not be used. However, the estimated coefficient of sunshine duration is statistically significant only with a $p$-value of 0.13 , and the coefficient of rainfall is insignificant. We conjecture that this is due to the limited variance of the dependent variable: only 11 percent of customers let their tickets expire. This is not surprising, considering that there is no systematic reason to let tickets go to waste if the day of the movie

has good weather. Instead, such days merely add noise to the potential impact of purchase-date weather on ex post errors.

We next turn our attention to subsamples of customers for whom movie-date weather turns out worse than potentially expected. In these subsamples, there is a greater scope for errors that may lead customers to let their tickets expire. We first restrict the sample to purchase decisions for which there was less sunshine duration on the day of the movie than on the day of purchase. This would be a negative surprise if customers were to extrapolate current weather conditions into the future. Second, we restrict the sample to customers for whom expected sunshine duration as predicted by 
Table 7: Purchase-Date Weather and the Probability that Tickets Expire

\begin{tabular}{|c|c|c|c|c|}
\hline \multirow[b]{2}{*}{ Sample Restrictions: } & \multicolumn{4}{|c|}{1 if Tickets Expire, 0 if Tickets Used } \\
\hline & $\begin{array}{l}\text { Full Sample } \\
\qquad(1)\end{array}$ & $\begin{array}{c}\text { Movie Sunshine } \\
\text { less than at Purchase } \\
(2)\end{array}$ & $\begin{array}{c}\text { Movie Sunshine } \\
\text { less than Predicted } \\
(3)\end{array}$ & $\begin{array}{l}\text { Rainfall on } \\
\text { the Movie-Date } \\
\text { (4) }\end{array}$ \\
\hline Avg. Sunshine Duration & $\begin{array}{c}0.18 \\
(0.12)\end{array}$ & $\begin{array}{l}0.53^{* *} \\
(0.22)\end{array}$ & $\begin{array}{l}0.45^{* * *} \\
(0.17)\end{array}$ & $\begin{array}{c}0.33^{*} \\
(0.17)\end{array}$ \\
\hline $\begin{array}{r}\text { Average Predicted Likelihood } \\
\text { At Sunshine Duration }=0 \\
\text { At Sunshine Duration }=1\end{array}$ & $\begin{array}{c}\text { that Tickets } \\
0.10 \\
0.13\end{array}$ & $\begin{array}{l}0.12 \\
0.21\end{array}$ & $\begin{array}{l}0.17 \\
0.26\end{array}$ & $\begin{array}{l}0.21 \\
0.29\end{array}$ \\
\hline Avg. Rainfall per Hour & $\begin{array}{r}-0.05 \\
(0.15)\end{array}$ & $\begin{array}{r}-0.05 \\
(0.26)\end{array}$ & $\begin{array}{c}-0.08 \\
(0.21)\end{array}$ & $\begin{array}{r}-0.03 \\
(0.22)\end{array}$ \\
\hline Sunshine before the Movie & $\begin{array}{c}-0.70^{* * *} \\
(0.12)\end{array}$ & $\begin{array}{c}-0.85^{* * *} \\
(0.20)\end{array}$ & $\begin{array}{c}-1.30^{* * *} \\
(0.39)\end{array}$ & $\begin{array}{c}-1.12^{* * *} \\
(0.26)\end{array}$ \\
\hline Rainfall during the Movie & $\begin{array}{l}0.13^{* * *} \\
(0.04)\end{array}$ & $\begin{array}{l}0.16^{* * *} \\
(0.05)\end{array}$ & $\begin{array}{l}0.18^{* * *} \\
(0.04)\end{array}$ & $\begin{array}{l}0.14^{* * *} \\
(0.04)\end{array}$ \\
\hline Temperature during the Movie & $\begin{array}{c}-0.11^{* * *} \\
(0.01)\end{array}$ & $\begin{array}{c}-0.14^{* * *} \\
(0.02)\end{array}$ & $\begin{array}{c}-0.16^{* * *} \\
(0.02)\end{array}$ & $\begin{array}{c}-0.14^{* * *} \\
(0.02)\end{array}$ \\
\hline Horizon FEs & yes & yes & yes & yes \\
\hline Forecast Variables & yes & yes & yes & yes \\
\hline Year \& Month FEs & yes & yes & yes & yes \\
\hline Movie-Date's Day-of-Week FEs & yes & yes & yes & yes \\
\hline Pseudo $R^{2}$ & 0.26 & 0.26 & 0.25 & 0.23 \\
\hline Observations & 3476 & 1479 & 1337 & 1169 \\
\hline
\end{tabular}

Notes: We report the coefficients and robust standard errors of Probit regressions of (3); see the text for details. Column 1 uses the full sample of advance sales in the years 2009 to 2011 for the estimation. In Column 2, we restrict the sample to orders for which average sunshine duration was lower on the day of the movie than on the day of purchase. In Column 3, we restrict the sample to orders for which average movie-date sunshine duration between 5 pm and $7 \mathrm{pm}$ was lower than predicted on the day of purchase using model (2). In Column 4, we restrict the sample to ticket orders for which there was positive precipitation on the day of the movie. We further report, for each sample, the average predicted likelihood that tickets expire if average purchase-date sunshine duration is 1 (completely sunny) and 0 (completely cloudy). Level of significance: ${ }^{*} p<0.10,{ }^{* *} p<0.05,{ }^{* * *} p<0.01$.

the forecast via model (2) is higher than the realized sunshine duration shortly before the movie. This would be a negative surprise if customers were to predict the weather using the forecast. And finally, we restrict the sample to date of movie's with positive rainfall. In these subsamples, 19 to 25 percent of customers let their tickets expire, so that there is a considerably higher fraction of "mistakes" than in the full sample.

Columns (2) to (4) of Table 7 show that, for the restricted samples, better purchase-date weather leads to a statistically significant increase in the probability that customers let their tickets go to waste. The estimated coefficients imply that it is on average 8 to 9 percent more likely that a customer lets her tickets expire when purchased on a completely sunny day (sunshine duration equals one) compared to a completely cloudy day (sunshine duration equals zero). These are sizable effects, considering that the average probabilities are between 19 and 25 percent. Overall, good purchase-date weather thus clearly increases the number of ex post mistakenly purchased tickets. 


\subsection{Salience of Consideration Sets}

The first psychological mechanism we discuss in detail is that good weather reminds customers of the possibility of visiting the theater. The idea is that customers face cognitive restrictions regarding the number of options they can consider at a given time and only consider an alternative if it "comes to mind." As such, the salience of a choice alternative determines the number of potential customers and consequently the size of the demand side. ${ }^{23}$ Thus, it seems natural that the choice option "outdoor movie theater" is particularly salient during good weather, of which sunshine duration is the most salient indicator.

In order to be consistent with all the findings presented thus far, consideration set salience needs to have the following three properties. First, the weather needs to scale the number of potential customers independently of the purchase timing, as we find that the effect of the weather on ticket orders is largely independent of the purchase horizon. This seems plausible, as reminders are naturally independent of the properties of the particular object of which one is reminded. Second, the reminder effect of weather has to operate (at least partially) via short-term changes in the weather in order to explain the effect of hourly changes in the weather on ticket orders. Again, this seems to be a sensible implication, as we would expect that it is the current state of the world that reminds individuals of options relevant in this state.

The third implication of the empirical findings in the context of consideration set salience is that those customers who are reminded of their option of buying tickets are more sensitive to the weather and thus let their tickets expire with greater probability. On the one hand, it seems plausible that predominantly marginal customers need a reminder to consider the outdoor cinema as a viable option for spending a night out. On the other hand, marginal customers should be expected to be more cautious in their purchasing behavior than the average customer and, for example, to avoid purchasing tickets many days ahead. This, however, would be at odds with the finding that good weather affects earlier and later ticket orders in the same way. It is moreover not obvious that customers who are reminded to visit the theater are necessarily the marginal ones. It seems equally plausible that sunny weather reminds those who highly value the outdoor movie experience to buy their tickets, as these are the ones who "lose" most when they forget to visit the theater. That the purchasing behavior of repeat customers, who presumably enjoy visiting the theater more than the average first-time visitor, is equally affected by the current weather as the behavior of the average customer could be interpreted in favor of the latter argument.

To further investigate the plausibility of the consideration set salience plus selection hypothesis, we can ask what fraction of those customers who were supposedly reminded to buy tickets at times of good weather would have to let their tickets expire for this hypothesis to be consistent with the

\footnotetext{
${ }^{23}$ See Eliaz and Spiegler (2011) for a recent theoretical treatment of the idea that marketing may direct customers' attention to certain choice alternatives. In addition, there are a number of empirical papers that demonstrate the importance of reminders for choice behavior. See, for example, Alba et al. (1991), Barber and Odean (2008), Chetty et al. (2009), Finkelstein (2009), or Karlan et al. (2010).
} 
data. Under the assumption that our findings are solely due to the reminder effect of the weather

$$
\operatorname{Pr}\left(\text { tickets expire } \mid y_{1}\right)=\frac{\operatorname{Pr}\left(\text { tickets expire } \mid y_{0}\right) y_{0}+\operatorname{Pr}(\text { tickets expire } \mid \Delta y) \Delta y}{y_{1}},
$$

where $y_{1}\left(y_{0}\right)$ denotes the number of ticket orders when the average sunshine equals 1 (equals 0 ) on the day of purchase, $\Delta y$ denotes the "marginal orders" $y_{1}-y_{0}$, and $\operatorname{Pr}$ (tickets expire $\left.\mid x\right)$ denotes the probability that tickets expire among the set of orders $x$. We assume that customers who buy their tickets even when the weather is completely cloudy have a different ex ante probability of not using their tickets than do the "selected" customers who only buy tickets when it is sunny. Because $\beta_{\text {sun }}$, the coefficient of average sunshine duration estimated in Table 3, is a semi-elasticity, we have $y_{1} \approx\left(1+\beta_{\text {sun }}\right) y_{0}$, which enables us to solve for $\operatorname{Pr}$ (tickets expire| $\left.\Delta y\right)$ as a function of $\beta_{\text {sun }}, \operatorname{Pr}\left(\right.$ tickets expire $\left.\mid y_{1}\right)$, and $\operatorname{Pr}\left(\right.$ tickets expire $\left.\mid y_{0}\right)$. Taking $\beta_{\text {sun }}=0.5^{24}$ and the estimated probabilities that tickets expire from Table 7 , we find that, to be consistent with the data, reminded customers need to let their tickets expire with a probability of 0.19 unconditional of movie-date weather and with a probability of up to 0.44 when it is raining on the day of the movie. Even though these values do not seem to be outright implausible they are rather high and imply that selected customers would take on a sizable risk when purchasing their tickets if the consideration set salience hypothesis were true.

We also test directly whether there is evidence that customers who order their tickets when the weather is good are different from customers who order tickets when the weather is bad. To this end, we regress average sunshine duration on the day of purchase on the customer characteristics that are observable in the data. Table 14 in Appendix E shows that neither a customer's age, nor her number of visits - in total or within a year - nor whether or not she had previously purchased tickets for a rainy day of the movie are related to sunshine duration on the day of purchase. Only those customers who previously had purchased a ticket on the day of the movie seem to order their tickets during slightly better weather conditions than others, but this coefficient is only statistically significant at a $p$-value of 0.13 . Even though this evidence is thus suggestive at best, it is consistent with a selection of more weather-sensitive customers at times of good weather, as those should also be the ones most likely to purchase their tickets on the day of the movie, when the weather risk is smallest.

\subsection{Projection Bias and Extrapolative Expectations}

Projection bias describes the tendency of individuals to underestimate the magnitude of a change in utility that may go along with a change in the state of the world. In our setting, projection bias describes the possibility that on a sunny day, potential customers dwell on the potential upside of enjoying a great summer night at the movies, but underestimate how unpleasant it is to sit outside on a rainy or cold evening. Similarly, on a cloudy or rainy day, customers have a hard time to

\footnotetext{
${ }^{24} \operatorname{Pr}($ tickets expire $\mid \Delta y)$ is decreasing in $\beta_{\text {sun }}$, so that assuming a $\beta_{\text {sun }}$ at the higher end of the estimates of Table 3 gives a lower bound for the probability that the tickets of marginal customers expire.
} 
imagine the full extent to which they would enjoy a summer night out. ${ }^{25}$

Based on earlier psychological work, Loewenstein et al. (2003) introduce a formalization of projection bias into the economics literature. Applied to our setting, their model of "simple projection bias" assumes that visiting the cinema on date $\tau, c$, provides instantaneous utility $u\left(c, w_{\tau}\right)$, which depends on the weather at $\tau, w_{\tau}$. Projection bias implies that customers who attempt to predict their future utility at an earlier date $t<\tau$ overestimate the degree to which future utility resembles the instantaneous utility they would receive under current weather conditions, given by $u\left(c, w_{t}\right)$. Assuming that customers form (rational) beliefs about the weather at $\tau$, described by the cdf $H_{t \tau}\left(w_{\tau}\right)$, a customer would thus exhibit projection bias if her estimated future utility $\tilde{U}(\cdot)$ were given by

$$
\tilde{U}\left(c, H_{t \tau}\left(w_{\tau}\right) \mid w_{t}\right)=\alpha u\left(c, w_{t}\right)+(1-\alpha) \int u\left(c, w_{\tau}\right) d H_{t \tau}\left(w_{\tau}\right) .
$$

Here, $\alpha \in[0,1]$ describes the degree of projection bias; (4) evidently nests expected utility for $\alpha=0$.

This formalization of projection bias assumes that customers form correct beliefs $H_{t \tau}\left(w_{\tau}\right)$ about the weather at $\tau$, but err in anticipating the degree to which changes in the weather affect their utility. An alternative interpretation of (4) could be that customers correctly anticipate the weather dependence of their utility, but put an excessive probability weight $\alpha$ on the event that the future weather is identical to the current weather (this has been pointed out by DellaVigna, 2009). ${ }^{26}$ Such extrapolative expectations and projection bias are observationally very similar in our setting, which is why we discuss their implications jointly.

The empirical findings are well in line with the predictions of the above model of projection bias or extrapolative expectations. The model predicts that good weather leads to an overvaluation of visiting the theater in the future (and bad weather leads to an undervaluation). Customers are hence expected to order tickets with a greater probability when it is sunny than when it is rainy; this holds for all purchase horizons as well as for short-run fluctuations in the weather. Moreover, as formally shown by Conlin et al. (2007), this also implies that customers who had ordered their tickets on a sunny day may realize ex post that their initial valuation of the night at the movie has been too high, resulting in a larger probability that their tickets will not be used.

Nevertheless, there are a few objections that may speak against the interpretation of the empirical findings as evidence for projection bias or extrapolative expectations. If projection bias were the explanation for our findings, we would expect that the dimension of utility that plausibly matters the most for utility — rainfall—predominantly explains the variations in ticket orders. ${ }^{27}$ In practice,

${ }^{25}$ In addition to the work by Conlin et al. (2007) and Busse et al. (2015) discussed in the Introduction, Simonsohn (2010) finds empirical evidence for projection bias. Another line of recent work structurally estimates the degree of projection bias as one of at least two parameters describing deviations from rational behavior (Kliger and Levy, 2008; Levy, 2010; Acland and Levy, 2015).

${ }^{26}$ Extrapolative and adaptive expectations have received renewed interest in the macroeconomics and finance literature. See, for example, Fuster et al. (2010) and Barberis et al. (2015) for recent theoretical applications. Benartzi (2001), Kaustia and Knüpfer (2008), Barber et al. (2009), or Choi et al. (2009) empirically show that individuals tend to choose assets with high current returns more frequently than other assets. See also Hommes (2011) for an overview of the related literature on heterogeneous expectations.

${ }^{27}$ In the survey, 82 percent of the customers stated that dry weather is either "very important" or "important" for enjoying the night out. 
it is the most salient dimension of weather - sunshine - which displays the strongest association with behavior, possibly favoring a salience story instead. At the same time, the data is not conclusive regarding which dimension of weather is, in fact, most important for customers' enjoyment of a movie. For example, movie-date sunshine duration seems to explain same-day ticket orders to a larger extent than movie-date rainfall (see Figure 1 for the correlation of same-day ticket orders and sunshine duration and Figure 7 in Appendix A for the correlation of same-day ticket orders and rainfall). Also, Table 7 suggests that all dimensions of movie-date weather are similarly important in explaining whether or not customers let their tickets expire.

Moreover, there are two reasons which may render it unlikely that customers extrapolate from the current weather when forming beliefs about future weather. First, most customers are locals and should be aware of the poor predictive power of the current weather for the future weather, especially many days in advance. Second, customers are explicitly warned on the ticketing website not to be too optimistic regarding future weather. Yet, these arguments, somewhat paradoxically, use rational reasoning to question a candidate psychological explanation for the observed behavior. Hence, they fall short in providing a data- or interpretation-driven reasoning why beliefs regarding the future should not irrationally assign excessive weight to the current state. ${ }^{28}$

\subsection{Salience of Product Attributes}

The third psychological mechanism we consider is the possibility that the current weather affects the salience of choice alternatives (as formalized by Bordalo et al., 2012, 2013 and Koszegi and Szeidl, 2013). This concept of salience describes the idea that the specific choice context determines the attributes of the available choice alternatives on which individuals will focus their attention. As the choice context changes, different attributes may become salient and, thus, receive higher decision weights. Henve, through salience the particular choice context governs the likelihoods with which choice alternatives are chosen. ${ }^{29}$

We pause to note that the concept of the "salience of product attributes" is very different from the idea of "consideration set salience" put forward earlier. The latter posits that salience affects choice behavior along the "extensive margin" by highlighting the choice alternatives that are actually available, determining which alternatives are included in the consideration set. In contrast, the idea here is that the salience of certain product attributes affects the likelihood with which an option is

\footnotetext{
${ }^{28}$ That individuals extrapolate from their current experience despite the negligible information content of these experiences has also been suggested by evidence from individual investment decisions cited in footnote 26 . It is hard to find a convincing argument why "expert knowledge" of the weather should de-bias individuals while knowledge of capital markets does not, despite the larger stakes in capital markets.

To us, it seems that a clean distinction between projection bias and extrapolative expectations is only possible in the setting at hand if beliefs are observable. For this reason, we asked customers to state their beliefs regarding future weather in the survey. Even though the survey data contains only 13 independent observations of the (expected) weather, there seems to be a robust positive correlation between current weather and customer's beliefs regarding tomorrow's weather. There is no robust correlation for other forecast horizons (see Table 15 in Appendix E). Due to the very limited statistical power underlying these correlations, however, we caution against drawing any firm conclusions from them (see Appendix C for further details).

${ }^{29}$ See, for example, Brown et al. (2010), Lacetera et al. (2012), or Hastings and Shapiro (2013) for empirical evidence that individuals focus more on some attributes than on others.
} 
chosen from the consideration set, corresponding to an effect of salience on choice behavior along the "intensive margin."

To clarify how we think about the salience of attributes, we adapt the formalization of "focusweighted utility" of Koszegi and Szeidl (2013) to choice under uncertainty. We consider a situation in which an individual may choose between different alternatives of how to spend an evening. These options are partly described by how appropriate they are for an evening with good weather (an attribute denoted by $g w$ ) or bad weather (an attribute denoted by bw). ${ }^{30}$ Besides these weatherrelated attributes, there may be others, such as the ease of conversing with friends, or the quality of the food and drink that can be ordered, all of which are elements of the attribute set $K$. Given this, the date- $t$ expected focus-weighted utility $\hat{U}$ of visiting the outdoor cinema-described by the multidimensional vector $\mathbf{c}$ - at date $\tau$ is assumed to be given by

$$
\hat{U}\left(c, H_{t \tau}\left(w_{\tau}\right)\right)=\int\left[\pi_{g w} u_{g w}\left(c_{g w}, w_{\tau}\right)+\pi_{b w} u_{b w}\left(c_{b w}, w_{\tau}\right)+\sum_{k \in K \backslash\{g w, b w\}} \pi_{k} u_{k}\left(c_{k}\right)\right] d H_{t \tau}\left(w_{\tau}\right) .
$$

Here, the consumption utility of attribute $x, u_{x}(\cdot)$, depends on the consumption level $c_{x} \in \mathbf{c}$ that a visit to the cinema entails for attribute $x$; in the weather-related dimensions, consumption utility is also determined by the realized weather $w_{\tau}$. Customers are assumed to hold rational date- $t$ beliefs regarding the future realizations of the weather, which are denoted by $H_{t \tau}\left(w_{\tau}\right)$. The focus-weight utility (5) hence only deviates from standard expected utility in terms of the attributes' "focus weights" $\pi_{x}$, that are assumed to be increasing in the attributes' salience.

The salience of an attribute is determined by how much this attribute "stands out" among all attributes within a consumer's choice context, which is typically assumed to include all choices in a customer's consideration set. Koszegi and Szeidl (2013) suggest that the salience of an attribute is increasing in the range of the attitude's possible consumption utilities across all elements of the consideration set. Hence, customers are assumed to focus on attributes for which the difference between the highest and the lowest possible (expected) consumption utility is high, while they rather neglect those attributes for which the maximum difference of expected consumption utilities is small. Watching a movie outdoors is plausibly a way to spend an evening that provides, compared with other alternatives, rather high good-weather consumption utility and rather low bad-weather consumption utility. Then, the maximum difference in the good-weather dimension of utility is high whenever the consideration set includes the alternative of visiting the cinema at times of beautiful weather. This increases the salience of the good-weather attribute, and thereby the salience of the

\footnotetext{
${ }^{30}$ As noted by Busse et al. (2015), how the product attributes are defined is an important part of this model's specification. Given the separate definition of good and bad weather attributes, we would intuitively expect that good current weather highlights the good weather attribute, a dimension in which the cinema is expected to provide a high consumption utility, hence causing customers to buy tickets. In contrast, unpleasant current weather may highlight the bad weather dimension in which the cinema provides very low consumption utility, potentially causing individuals to shy away from ordering tickets. In contrast, if we were to define only a single weather-related attribute, this attribute could be highlighted by both, unusually good and unusually bad weather. In this case, either type of extreme weather could cause an increase in ticket orders, which seems counter-intuitive and is inconsistent with our results.
} 
potential upside of visiting the theater. Conversely, if the consideration set includes the option of visiting the outdoor theater at times of unpleasant weather, the bad-weather attribute is expected to receive a high focus weight and with it the potential downside of sitting outside when it pours.

Our empirical findings can thus potentially be explained by the current weather's increasing the salience of weather-related product attributes. For this to be the case, however, the option of visiting the cinema evaluated at current weather conditions must enter the consideration set, even though the consumer is considering buying a ticket for some future date with still uncertain weather conditions. It seems quite plausible that a potential customer considering ordering tickets for a future date imagines how enjoyable it would be to visit the cinema today. This, then, would lead to the observed positive association between pleasant purchase-date weather and ticket orders. Moreover, whenever the weather changes between the day of purchase and the day of the movie, the focus weights would change. A customer who experiences less than ideal weather conditions on the day of the movie may find out ex post that due to good weather at the time of purchase, she had been focusing too much on the potential upside of spending a beautiful summer night outside. In this way, the changing salience of product attributes may also explain the higher willingness to let tickets expire for those customers who had purchased their tickets on a sunny day. ${ }^{31}$

There is an additional prediction from the psychological mechanism of "salience of product attributes" that can be used to differentiate this mechanism from the other two psychological theories we have considered earlier. This prediction is based on the assumption that the current weather may change the salience of weather-related product attributes, but does not disturb the expected consumption utilities of these attributes. As a consequence, highlighting the good-weather attribute of the movie theater should lead to a more pronounced increase in ticket orders when the weather is indeed forecast to be beautiful. Conversely, bad purchase-date weather should result in a stronger decrease in ticket orders if the future weather is expected to be unpleasant. ${ }^{32}$

We examine this prediction by testing whether the effect of current sunshine duration and rainfall on ticket orders depends on the (expected) movie-date weather. To this end, we augment the main panel specification (1) by interactions of the weather variables with dummy variables that equal one when the movie-date weather may be expected to be pleasant. Our first indicator of pleasant

\footnotetext{
${ }^{31}$ It is more difficult to explain the empirical findings of this paper with the definition of salience put forward by Bordalo et al. (2012, 2013), which allows the salience of one attribute to differ across choice alternatives. In their setting, the salience of an alternative's attribute is increasing in the difference between the attribute's consumption utility for this alternative and the average consumption utility of the attribute across the elements of the consideration set. Following this definition, good weather on the day of purchase may increase the average consumption utility for the good-weather attribute, and, thus, decrease the salience of the good-weather attribute for the alternative of visiting the theater in the future. Even though the models of Bordalo et al. (2012, 2013) and Koszegi and Szeidl (2013) share the intuition that attributes which "stand out" should be more salient, the specific formalization of this idea may thus lead to different empirical implications. Note, also, that for both conceptualizations of salience, it is important which choice alternatives enter the consideration set. See Busse et al. (2015) for an extensive discussion of this issue.

${ }^{32}$ Obviously, it may be the case that purchase-date weather simultaneously increases the salience of product attributes and distorts beliefs regarding future weather in the direction of the current weather. However, we argue in Section 5.3 that distorted beliefs are sufficient to explain all empirical findings thus far. Occam's Razor would hence lead us to prefer such an explanation to the more complex combination of "salience of product attributes" and distorted beliefs.
} 
Table 8: Effect of Purchase-Date Weather on Ticket Orders Conditional on Movie-Date Weather

\begin{tabular}{|c|c|c|c|}
\hline & \multicolumn{3}{|c|}{ Ticket Orders (1-4 Days Ahead) } \\
\hline Avg. Sunshine Duration & $\begin{array}{l}0.53^{* * *} \\
(0.17)\end{array}$ & $\begin{array}{l}0.52^{* * *} \\
(0.17)\end{array}$ & $\begin{array}{r}0.32^{*} \\
(0.18)\end{array}$ \\
\hline × I(Forecast "Sunny" or "Partly Sunny") & $\begin{array}{r}-0.02 \\
(0.18)\end{array}$ & & \\
\hline$\times$ I(Movie-Date Sunshine $>$ Median $)$ & & $\begin{array}{r}-0.01 \\
(0.21)\end{array}$ & \\
\hline × I(Movie-Date Rainfall = 0) & & & $\begin{array}{c}0.29 \\
(0.21)\end{array}$ \\
\hline Avg. Rainfall per Hour & $\begin{array}{r}-0.45^{*} \\
(0.24)\end{array}$ & $\begin{array}{r}-0.15 \\
(0.23)\end{array}$ & $\begin{array}{r}-0.17 \\
(0.21)\end{array}$ \\
\hline × I(Forecast "Sunny" or "Partly Sunny") & $\begin{array}{c}0.33 \\
(0.29)\end{array}$ & & \\
\hline × I(Movie-Date Sunshine $>$ Median $)$ & & $\begin{array}{r}-0.18 \\
(0.32)\end{array}$ & \\
\hline$\times$ I $($ Movie-Date Rainfall = 0) & & & $\begin{array}{r}-0.24 \\
(0.31)\end{array}$ \\
\hline Avg. Sunshine Past 14 Days & $\begin{array}{r}-0.04 \\
(0.88)\end{array}$ & $\begin{array}{c}0.03 \\
(0.88)\end{array}$ & $\begin{array}{c}0.10 \\
(0.89)\end{array}$ \\
\hline Avg. Rainfall Past 14 Days & $\begin{array}{r}-1.91 \\
(1.56)\end{array}$ & $\begin{array}{l}-1.85 \\
(1.52)\end{array}$ & $\begin{array}{r}-1.62 \\
(1.56)\end{array}$ \\
\hline Forecast Variables & yes & yes & yes \\
\hline Horizon FEs & yes & yes & yes \\
\hline Movie-Date FEs & yes & yes & yes \\
\hline Observations & 1353 & 1353 & 1353 \\
\hline
\end{tabular}

Notes: We report the coefficients and standard errors (clustered on the movie-date level) from Poisson panel regressions of (1). The specification is the same as in Column 1 of Table 3, except that interactions of purchase-date weather variables and indicators that equal 1 when movie-date weather is (expected to be) pleasant are added to the set of independent variables. This indicator equals 1 if movie-date weather is forecast to be either "sunny" or "partly sunny" (in Column 1), if movie-date sunshine duration is above its median (in Column 2), or if the weather on the day of the movie was dry (in Column 3). Level of significance: ${ }^{*} p<0.10,{ }^{* *} p<0.05,{ }^{* * *} p<0.01$.

future weather is a forecast of either "sunny" or "partly sunny" conditions for the day of the movie. The second and third indicators use ex post realizations of the weather as proxies for the expected weather. Specifically, the second indicator of good movie-date weather equals one when movie-date sunshine duration is greater than the median, and the third indicator equals one whenever there is no rainfall on the day of the movie. To ensure that customers are able to form reasonably accurate expectations regarding movie-date weather, we restrict the sample to ticket orders between one and four days in advance. ${ }^{33}$

Overall, Table 8 shows at best suggestive evidence for the prediction that the weather dependence of customers' purchase behavior is related to expected future weather conditions. Good expected

\footnotetext{
${ }^{33}$ Note that this test crucially relies on the fact that tickets are valid on the day of the movie only, which allows us to use variation in expected weather to proxy for variation in expected consumption utility. Such credible variation in expected utility is presumably much harder to find for durable goods, so that it may be a challenge to apply the same test within choice contexts like the ones studied by Conlin et al. (2007) and Busse et al. (2015).
} 
weather strengthens the effect of sunshine duration on orders only for the specification in Column 3 , where good expected weather is proxied by the absence of rainfall on the day of the movie. Otherwise, the coefficient of sunshine duration is very robustly independent of the expected weather indicators. For rainfall, we expect to find negative coefficients of higher magnitudes when the expected weather is unfavorable for spending a night outside. This, however, is only the case in Column 1 which shows that the effect of current rainfall on purchases is only significantly negative when the forecast predicts weather conditions worse than "sunny" or "partly sunny." The coefficients of the rainfall interactions in Columns 2 and 3 have the wrong sign.

\section{Conclusion}

In this article, we demonstrate that even simple forward-looking decisions may be influenced by psychological biases. We show that advance sales of an outdoor movie theater are caused by weather conditions at the time of purchase even though the latter is irrelevant for the experience of visiting the theater in the future. This finding is consistent with customers being exposed to either projection bias, extrapolative expectations, or salience effects of the weather (consideration set salience or salience of product attributes) when they make their purchasing decisions. Moreover, we have utilized the perishable nature of the movie tickets to test an implication of the "salience of product attributes" explanation that distinguishes this theory from the other psychological mechanisms we considered. Yet, the evidence of this test is too weak to make a definite statement regarding whether "product attribute salience" or the other psychological mechanisms are more in line with our findings. Overall, there thus remains some uncertainty as to which specific psychological mechanism affects the customers' intertemporal decision making. An important task for future work is therefore to find testable implications as well as empirical settings which allow further teasing apart of the alternative psychological theories considered in this paper. ${ }^{34}$

The exact nature of the specific psychological factor(s) that affect intertemporal choice has profound consequences for the design of policies that may help people to make better decisions. ${ }^{35}$ If projection bias was an important driver of choice behavior, for example, individuals could benefit from "cooling-off" periods that would allow them to re-evaluate their choices in different states of the world and to potentially reverse their decisions. If individuals' beliefs assign excessive probability weight to the current state, it would better serve peoples' interests if they were informed about those states of the world that are both likely and "different" from today's conditions. And finally, if individuals have difficulty recalling the relevant choice alternatives, they may benefit from receiving condensed information on viable options.

While all of these policies should rather be applied to more important decision problems than the planning of a night out, we believe that such simple situations provide fruitful settings to single out the most probable errors individuals make in intertemporal choice problems.

\footnotetext{
${ }^{34}$ In Appendix $\mathrm{C}$ we discuss empirical strategies which would be suitable for achieving this goal in the setting considered here, even though we either lack the statistical power or the data necessary to implement them.

${ }^{35}$ See Camerer et al., 2003, for a detailed discussion of more specific variants of these policies.
} 


\section{References}

Acland, D. And M. R. Levy (2015): "Naiveté, Projection Bias, and Habit Formation in Gym Attendance," Management Science, 61, 146-160.

Alba, J. W., J. W. Hutchinson, And J. G. J. Lynch (1991): "Memory and Decision Making," in Handbook of Consumer Behavior, ed. by T. S. Robertson and H. H. Kassarjian, Englewood Cliffs and NJ: Prentice-Hall, 1-49.

Allison, P. D. (1984): Event History Analysis: Regression for Longitudinal Event Data, Beverly Hills (CA): Sage Publications.

Barber, B. M. And T. Odean (2008): "All That Glitters: The Effect of Attention and News on the Buying Behavior of Individual and Institutional Investors," The Review of Financial Studies, $21,785-818$.

Barber, B. M., T. Odean, And N. Zhu (2009): "Systematic Noise," Journal of Financial Markets, 12, 547-569.

Barberis, N., R. Greenwood, L. Jin, And A. Shleifer (2015): "X-CAPM: An Extrapolative Capital Asset Pricing Model," Journal of Financial Economics, 115, 1-24.

Benartzi, S. (2001): "Excessive Extrapolation and the Allocation of 401(k) Accounts to Company Stock," Journal of Finance, 56, 1747-1764.

Bordalo, P., N. Gennaioli, and A. Shleifer (2012): "Salience Theory of Choice Under Risk," Quarterly Journal of Economics, 127, 1243-1285.

— (2013): "Salience and Consumer Choice," Journal of Political Economy, 121, 803-843.

Brown, J., T. Hossain, and J. Morgan (2010): "Shrouded Attributes and Information Suppression: Evidence from the Field," Quarterly Journal of Economics, 125, 859-876.

Busse, M. R., D. G. Pope, J. C. Pope, and J. Silva-Risso (2015): "The Psychological Effect of Weather on Car Purchases," The Quarterly Journal of Economics, 130, 371-414.

Camerer, C., S. Issacharoff, G. Loewenstein, T. O’Donoghue, and M. Rabin (2003): "Regulation for Conservatives: Behavioral Economics and the Case for 'Asymmetric Paternalism'," University of Pennsylvania Law Review, 151, 1211-1254.

Cameron, A. C. and P. K. Trivedi (1998): Regression Analysis of Count Data, Cambridge (UK): Cambridge University Press.

Chetty, R., A. Looney, And K. Kroft (2009): "Salience and Taxation: Theory and Evidence," American Economic Review, 99, 1145-1177. 
Choi, J. J., D. Laibson, B. C. Madrian, and A. Metrick (2009): "Reinforcement Learning and Savings Behavior," Journal of Finance, 64, 2515-2534.

Conlin, M., T. O’Donoghue, and T. J. Vogelsang (2007): "Projection Bias in Catalog Orders," American Economic Review, 97, 1217-1249.

DellaVigna, S. (2009): "Psychology and Economics: Evidence from the Field," Journal of Economic Literature, 47, 315-372.

Eliaz, K. AND R. Spiegler (2011): "Consideration Sets and Competitive Marketing," The Review of Economic Studies, 78, 235-262.

Finkelstein, A. (2009): "E-ZTAX: Tax Salience and Tax Rates," Quarterly Journal of Economics, 124, 969-1010.

Fuster, A., D. Laibson, And B. Mendel (2010): "Natural Expectations and Macroeconomic Fluctuations," Journal of Economic Perspectives, 24, 67-84.

Hastings, J. S. And J. M. Shapiro (2013): "Fungibility and Consumer Choice: Evidence from Commodity Price Shocks," Quarterly Journal of Economics, 128, 1449-1498.

Hommes, C. (2011): "The Heterogeneous Expectations Hypothesis: Some Evidence from the Lab," Journal of Economic Dynamics and Control, 35, 1-24.

Jenkins, S. P. (2005): Survival Analysis, University of Essex (Colchester).

Karlan, D., M. McConnell, S. Mullainathan, and J. Zinman (2010): "Getting to the Top of Mind: How Reminders Increase Saving," NBER Working Paper, 2010.

Kaustia, M. And S. KnÜpfer (2008): "Do Investors Overweight Personal Experience? Evidence from IPO Subscriptions," Journal of Finance, 63, 2679-2702.

Kliger, D. And O. Levy (2008): "Projection Bias by Investors: A Market Approach," Journal of Economic Behavior \& Organization, 66, 657-668.

Koszegi, B. And A. Szeidl (2013): "A Model of Focusing in Economic Choice," Quarterly Journal of Economics, 128, 53-104.

Lacetera, N., D. G. Pope, and J. R. Sydnor (2012): "Heuristic Thinking and Limited Attention in the Car Market," American Economic Review, 102, 2206-2236.

Levy, M. (2010): “An Empirical Analysis of Biases in Cigarette Addiction," Working Paper.

Loewenstein, G., T. O’Donoghue, and M. Rabin (2003): "Projection Bias in Predicting Future Utility," Quarterly Journal of Economics, 118, 1209-1248.

Simonsohn, U. (2010): "Weather to Go to College," Economic Journal, 120, 270-280. 


\section{Appendix (for online publication)}

\section{A. Illustrative Evidence With Rainfall as the Relevant Weather Dimension}

In this section, we graphically illustrate the correlations between atypical rainfall and atypical ticket orders; the discussion thereby parallels the one regarding the correlation between atypical sunshine duration and atypical ticket orders in Section 3.1 of the main text. ${ }^{36}$ One notable difference is that it is infeasible to split the data by deciles of rainfall, because almost 50 percent of the days in our sample had no rainfall. Instead, all figures shown in this section display the averages of atypical ticket orders for atypical rainfall above and below its median.

Figure 7: Same-Day Ticket Orders and Movie-Date Rainfall

This figure plots the average of residuals of log online ticket orders (termed "atypical ticket orders" in the text) on the day of the movie night for residual movie-date rainfall (termed "atypical rainfall" in the text) above and below its median. Residuals are the values of the respective variable net of their movie-date and purchase-horizon specific conditional means.

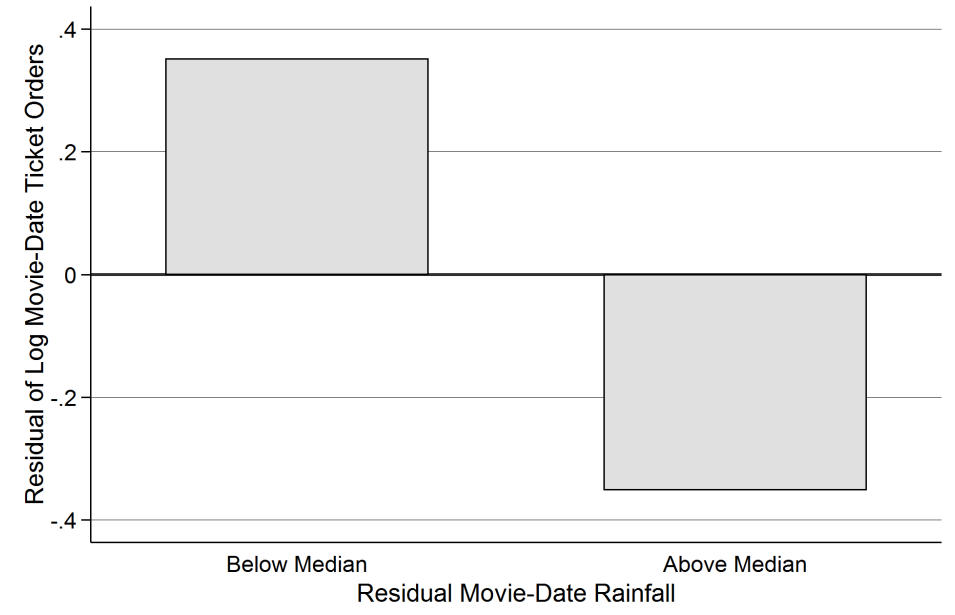

Figure 7 is the counterpart of Panel (a) of Figure 1, and displays the average of atypical sameday ticket orders for atypical movie-date rainfall above and below its median. As in the case of sunshine duration, atypical same-day orders are higher when the weather is good, and hence negatively correlated with atypical movie-date rainfall. Specifically, atypical ticket orders on those movie days with below median rainfall are, on average, 0.8 log points larger than on days with above median rainfall. The magnitude of the effect of atypical movie-date rainfall on same-day ticket orders is thus exactly half as large as the effect of atypical movie-date sunshine duration on same-day ticket orders.

\footnotetext{
${ }^{36}$ As atypical sunshine duration, atypical rainfall is defined as the residual of a regression of rainfall on movie-date and purchase-horizon fixed effects for a window of 29 days between the day of the movie and the date 28 days prior to the day of the movie. Atypical rainfall is hence the deviation of rainfall from its four week average prior to (and including) the day of the movie.
} 
Figure 8: Movie-Date Rainfall and Advance Ticket Orders

This figure plots the average of residuals of log ticket orders (termed "atypical ticket orders" in the text), separately for orders one to four days in advance, for residual movie-date rainfall (termed "atypical rainfall" in the text) above and below its median. See the notes of Figure 7 for the definitions of the variable.

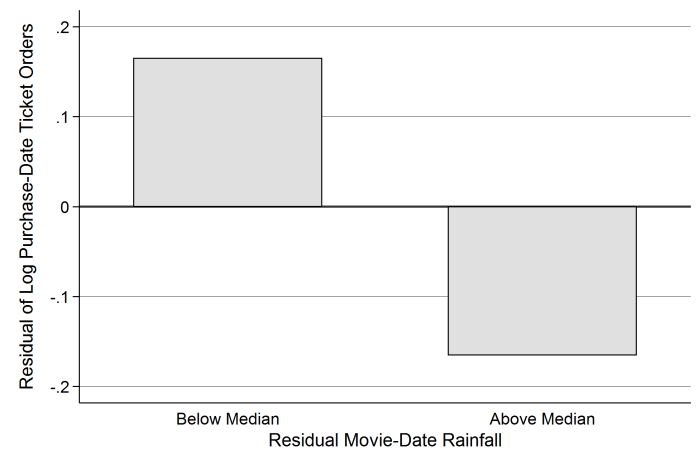

(a) Ticket Orders One Day Ahead

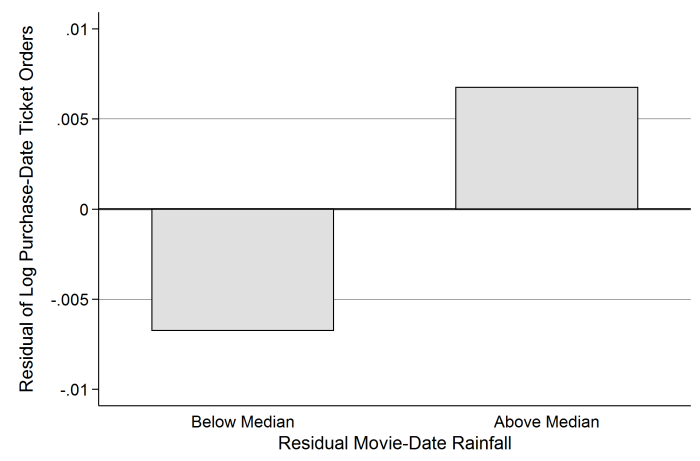

(c) Ticket Orders Three Days Ahead

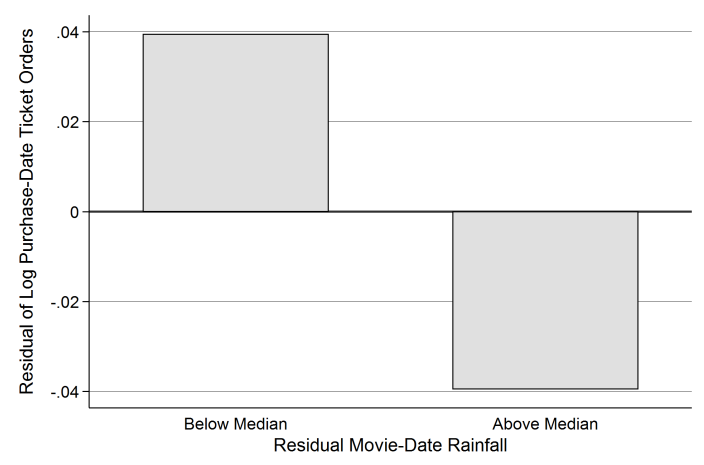

(b) Ticket Orders Two Days Ahead

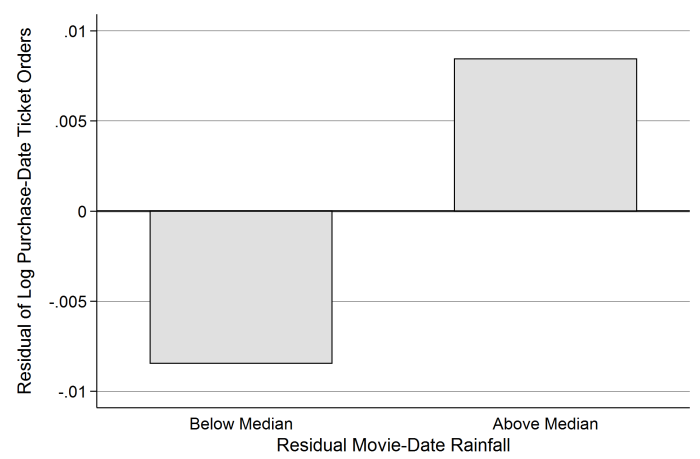

(d) Ticket Orders Four Days Ahead

If the absence of rainfall were an important determinant of customers' utility from visiting the theater, we would expect them to carefully forecast the future rainfall before making a purchasing decision. If these forecasts are on average correct, we would expect to find a negative correlation between realized movie-date rainfall and advance ticket orders as well. Figure 8 provides an analog to Figure 2 in that it displays the average of atypical ticket orders between one and four days ahead of the day of the movie for movie-date atypical rainfall above and below its median. It becomes apparent that the magnitude of the negative correlation between movie-date rainfall and advance ticket orders declines for orders between one and two days before the movie. For ticket orders three days before and earlier, this correlation ceases to exist. The correlation between movie-date rainfall and advance ticket orders seems thus to be weaker than the corresponding correlations of sunshine duration and ticket orders. This may be the case, because rainfall is supposedly more difficult to predict than more general weather patterns. Also, the general weather patterns described by a forecast probability of rain of, for example, 60 percent are likely to be more accurately reflected by the realized sunshine duration (or, equivalently, the degree of cloudiness) than by whether or not it actually rains. 
Figure 9: Purchase-Date Rainfall and Advance Ticket Orders

This figure plots the average of residuals of log ticket orders (termed "atypical ticket orders" in the text), separately for orders one to four days in advance, for residual purchase-date rainfall (termed "atypical rainfall" in the text) above and below its median. See the notes of Figure 7 for the definitions of the variables.

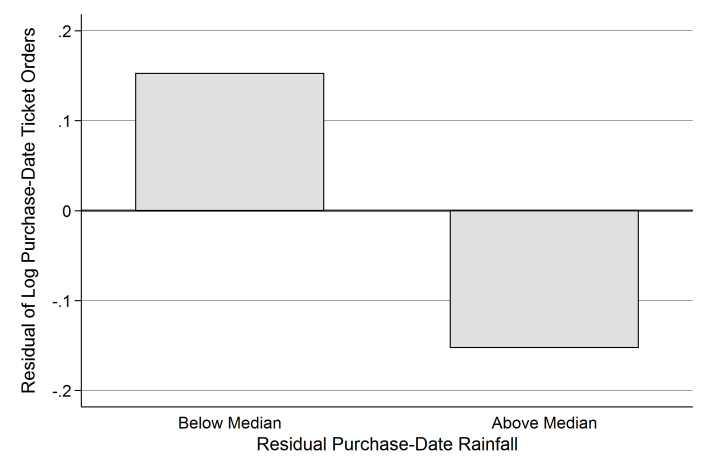

(a) Ticket Orders One Day Ahead

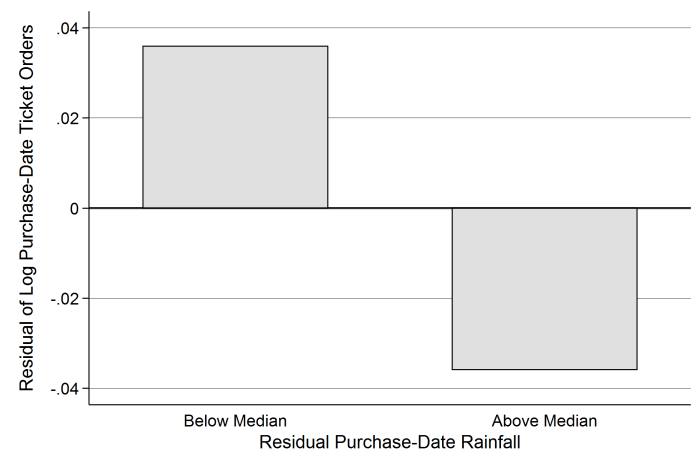

(c) Ticket Orders Three Days Ahead

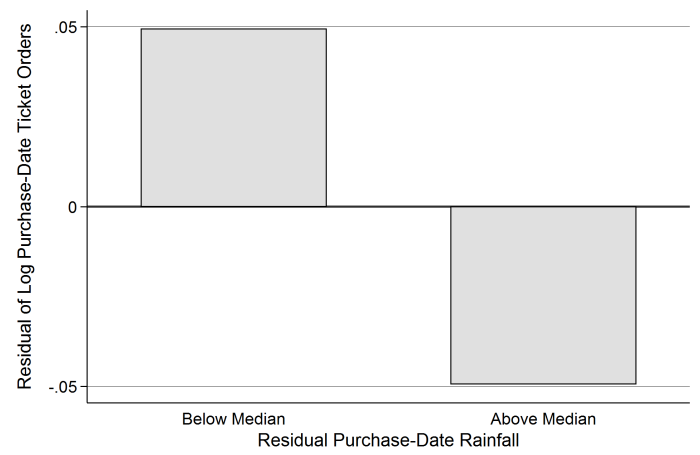

(b) Ticket Orders Two Days Ahead

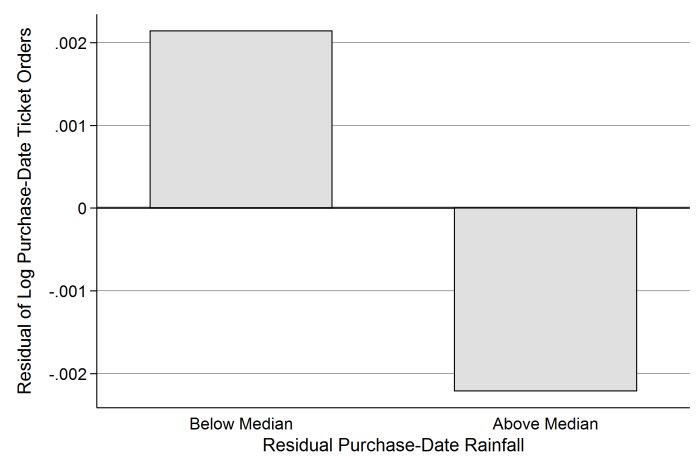

(d) Ticket Orders Four Days Ahead

Finally, we illustrate the possibility that customers' purchasing decisions not only depend on the realized or expected weather, but also on the weather at the time of purchase, even if it is irrelevant for the utility of watching the movie outdoors on a future date. Figure 9 mirrors Figure 3 in the main text in showing the average of atypical ticket orders between one and four days before the movie, but this time for atypical purchase-date rainfall above and below its median. The four panels of Figure 9 show that purchase-date rainfall is (in contrast to movie-date rainfall) negatively correlated with ticket orders across all purchase horizons, even if this correlation becomes extremely small for ticket orders four days ahead.

We conclude that the correlations of ticket orders and rainfall display similar properties as the correlations, discussed in the main text, between ticket orders and sunshine duration. Despite this general similarity the magnitudes of the correlations between ticket orders and rainfall are clearly smaller than those between ticket orders and sunshine duration. As alluded to above, this does not necessarily mean that customers care less about rainfall than they care about sunshine. Instead, the smaller correlation between rainfall and ticket orders may be due to the lower variation of rainfall along the "extensive" margin of whether or not it rains, and the accompanying lower 
statistical power of this weather variable. In addition, the smaller magnitude of the correlations may reflect the possibility that sunshine duration better represents general weather patterns than the observation of whether or not it is raining.

\section{B. Alternative Empirical Approaches}

\section{B.1. Event History Analysis}

Event history analysis constitutes an alternative method to estimate the effect of purchase-date weather on ticket orders, as it models the factors that determine a member of a population at risk (prospective customers) to experience an event (order tickets). As such, event history analysis makes use of individual-level data, in contrast to count data techniques, which employ aggregate data.

The central statistic of this empirical approach is the daily, discrete-time, hazard rate $h_{t \tau}$ at which a representative customer orders tickets at $t$ for the day of the movie $\tau$. Depending on the definition of the population at risk, there are two possible ways to interpret the hazard rate in our setting. First, the population at risk may be equated to the set of potential customers who actively consider buying tickets for the movie theater. This definition of the population at risk implies a daily hazard rate that is equal to the potential customers' purchasing probability. Alternatively, the population at risk may be equalized with the entire population (whether or not they are actively considering visiting the cinema). The daily hazard rate for this population at risk is the product of the purchasing probability of the potential customers with the rate at which individuals from the entire population start to actively consider visiting the movie theater. Regardless of its interpretation, we maintain the assumption underlying the Poisson model (1), that the continuous-time hazard is piecewise exponential (the continuous-time proportional hazard assumption). This implies that the daily, discrete-time, hazard $h_{t \tau}$ is given by

$$
h_{t \tau}=1-\exp \left[-\exp \left(\text { Weather }_{\mathbf{t}}^{\prime} \boldsymbol{\beta}_{\boldsymbol{W}}+\text { Forecast }_{\mathbf{t} \tau}^{\prime} \boldsymbol{\beta}_{\boldsymbol{F}}+\mu_{\tau}+\delta_{t \tau}\right)\right] \text {, }
$$

which can be transformed into the complementary log-log form for estimation via maximum likelihood (see Jenkins, 2005, p. 41 ff.).

Standard empirical procedures for estimating (6) require the observation of a random sample of the population at risk. ${ }^{37}$ It is not clear whether this is the case for the data available, as only those customers are observed who actually order tickets. Nevertheless, one possibility could be to define those customers as being at risk of purchasing tickets at $t$ who have not purchased their ticket for a particular movie yet but will either buy at $t$ or later. This means that the number of individuals at risk of buying a ticket at $t$ for the movie at $\tau$ is given by $\sum_{t^{\prime} \in[t, \tau]} \hat{y}_{t^{\prime} \tau}$, where $\hat{y}_{t^{\prime} \tau}$ denotes the number of ticket orders for the day of the movie $\tau$ observed as of the date $t^{\prime}$. If we were willing to assume that time-varying covariates (like the weather) solely affect the timing of purchases,

\footnotetext{
$\overline{{ }^{37} \text { Right censoring or left truncation can easily }}$ be accommodated, but neither is a problem here.
} 
but not the expected number of total tickets sold, the set of customers is a random sample of the set of potential customers. Then, standard methods can be used to estimate the hazard rate $h_{t \tau}$. However, if time-varying covariates affect the total number of customers who order at $t$ or later, the set of actual customers represents a selected sample of the population at risk, and the hazard rate cannot be estimated with standard procedures. ${ }^{38}$

For the time being, we assume that our sample allows consistent estimation of the daily hazard rate $h_{t \tau}$ via the standard method, a binary regression model with complementary log-log link function. To run this regression, the dataset needs to be organized in person-period format. This means that for each customer who orders a ticket at $t$, an observation is created for each date between the day of purchase $t$ and the date 28 days prior to the movie. ${ }^{39}$ After the purchase-date, the customer drops out of the sample, as no longer being "at risk" for purchasing a ticket. For each observation created, a "purchase indicator" equals 0 for the dates prior to the day of purchase and 1 on the day of purchase. This dataset is then merged with the time-varying covariates, and (6) is estimated by performing a binary regression of the "purchase indicator" on the set of covariates (see Jenkins, 2005, or Allison, 1984, for details). Because (6) contains movie-date fixed effects, the effect of the covariates on the hazard rate is identified via the time variation of the covariates.

Table 9 displays the results from the estimation of (6) with the same empirical specifications as the main results reported in Table 3. Apparently, the coefficients estimated via an event history analysis are very similar to those estimated via the Poisson panel regressions. In particular, the coefficient of sunshine duration in Table 9 implies that a member of the "population at risk" is 50 percent more likely to order tickets on a day with completely clear skies than on a completely cloudy day. This corresponds exactly to the predicted percentage increase in ticket orders estimated via the count models in the main body of the text. The effect of purchase-date rainfall estimated via event history models is negative, but statistically insignificant. Despite the potential selection problem discussed above, we thus arrive at very similar empirical findings irrespective of whether we employ an event history or a count data approach for the estimations.

Another possibility of utilizing event history analysis is to analyze purchase behavior within days (across hours). Here, the potential selection problem from the above can be curtailed by considering only those individuals to be at risk of purchasing tickets that have not yet but will buy tickets on the same day for the same movie. ${ }^{40}$ That is, we estimate the hourly hazard rate of ticket orders for

\footnotetext{
${ }^{38}$ It is unlikely that sample selection is not an issue here. In Section 4.2 we have shown that good weather tends to increase the total number of tickets sold and thus does not solely affect purchase timing. In addition, the majority of tickets are ordered on the day of the movie, and we have shown in Figure 1 that same-day ticket orders vary considerably with the movie-date weather. As a consequence, defining those customers at risk of purchasing a ticket who have not yet ordered their ticket leads to a large "population at risk" for movies, for which movie-date weather turns out to be good, and vice versa for dates of movies with bad weather.

${ }^{39}$ Individuals with online ticket orders on the day of the movie are also considered. This is because neglecting these customers would lead to a "population at risk" one day ahead of the day of the movie that only consists of customers ordering on this date. The "empirical hazard rate" would then uniformly equal 1 for all observations one day ahead, so that all these observations would drop from the sample as they would be perfectly explained by the purchase-horizon fixed effect.

${ }^{40}$ This "population at risk" is most likely selected nevertheless, but assuming that the arrival rate of customers is independent of the variation of covariates within a day seems more reasonable than assuming the independence
} 
Table 9: Event History Estimates of the Effect of Weather on Ticket Orders

\begin{tabular}{|c|c|c|c|c|}
\hline & \multicolumn{4}{|c|}{ Daily Ticket Orders } \\
\hline & \multicolumn{2}{|c|}{ 1-4 Days Ahead } & \multicolumn{2}{|c|}{ 1-28 Days Ahead } \\
\hline & (1) & $(2)$ & (3) & $(4)$ \\
\hline Avg. Sunshine Duration & $\begin{array}{l}0.50^{* * *} \\
(0.11)\end{array}$ & $\begin{array}{l}0.50^{* * *} \\
(0.10)\end{array}$ & $\begin{array}{l}0.47^{* * *} \\
(0.07)\end{array}$ & $\begin{array}{l}0.50^{* * *} \\
(0.07)\end{array}$ \\
\hline Avg. Rainfall per Hour & $\begin{array}{c}-0.17 \\
(0.18)\end{array}$ & $\begin{array}{c}-0.11 \\
(0.16)\end{array}$ & $\begin{array}{c}-0.11 \\
(0.09)\end{array}$ & $\begin{array}{c}-0.11 \\
(0.10)\end{array}$ \\
\hline Avg. Sunshine Past 14 Days & $\begin{array}{c}-0.26 \\
(0.80)\end{array}$ & $\begin{array}{c}-0.57 \\
(0.87)\end{array}$ & $\begin{array}{l}0.91^{* * *} \\
(0.23)\end{array}$ & $\begin{array}{l}0.90^{* * *} \\
(0.25)\end{array}$ \\
\hline Avg. Rainfall Past 14 Days & $\begin{array}{c}-1.05 \\
(1.51)\end{array}$ & $\begin{array}{c}-1.38 \\
(1.61)\end{array}$ & $\begin{array}{r}-1.00^{*} \\
(0.55)\end{array}$ & $\begin{array}{c}-1.30^{* *} \\
(0.54)\end{array}$ \\
\hline Forecast Maxtemp. & $\begin{array}{l}0.00 \\
(0.02)\end{array}$ & & $\begin{array}{l}0.07^{* * *} \\
(0.02)\end{array}$ & \\
\hline Forecast Mintemp. & $\begin{array}{c}-0.01 \\
(0.02)\end{array}$ & & $\begin{array}{c}-0.02 \\
(0.02)\end{array}$ & \\
\hline Symbol Partly Sunny & $\begin{array}{c}0.12 \\
(0.08)\end{array}$ & & $\begin{array}{r}-0.15^{*} \\
(0.09)\end{array}$ & \\
\hline Symbol T-Storm & $\begin{array}{c}0.06 \\
(0.12)\end{array}$ & & $\begin{array}{c}-0.31^{* *} \\
(0.12)\end{array}$ & \\
\hline Symbol Shower & $\begin{array}{c}0.12 \\
(0.13)\end{array}$ & & $\begin{array}{c}-0.26^{* *} \\
(0.11)\end{array}$ & \\
\hline Symbol Rain & $\begin{array}{c}0.10 \\
(0.34)\end{array}$ & & $\begin{array}{c}-0.38 \\
(0.31)\end{array}$ & \\
\hline 1 Day Ahead $\times$ Movie-Date Sunshine & & $\begin{array}{c}0.19 \\
(0.26)\end{array}$ & & $\begin{array}{c}-0.23 \\
(0.66)\end{array}$ \\
\hline 1 Day Ahead $\times$ Movie-Date Rainfall & & $\begin{array}{r}-0.68^{*} \\
(0.35)\end{array}$ & & $\begin{array}{c}-1.35^{* *} \\
(0.60)\end{array}$ \\
\hline 2 Days Ahead $\times$ Movie-Date Sunshine & & $\begin{array}{c}0.11 \\
(0.23)\end{array}$ & & $\begin{array}{r}-0.39 \\
(0.65)\end{array}$ \\
\hline 2 Days Ahead $\times$ Movie-Date Rainfall & & $\begin{array}{c}-0.09 \\
(0.29)\end{array}$ & & $\begin{array}{c}-0.69 \\
(0.62)\end{array}$ \\
\hline 3 Days Ahead $\times$ Movie-Date Sunshine & & $\begin{array}{c}-0.15 \\
(0.24)\end{array}$ & & $\begin{array}{c}-0.68 \\
(0.65)\end{array}$ \\
\hline 3 Days Ahead $\times$ Movie-Date Rainfall & & $\begin{array}{c}-0.09 \\
(0.35)\end{array}$ & & $\begin{array}{c}-0.58 \\
(0.64)\end{array}$ \\
\hline $\begin{array}{l}\text { Horizon FEs } \\
\text { Horizon } \times \text { Movie-Date We }\end{array}$ & yes & yes & yes & yes \\
\hline $\begin{array}{l}\text { Horizon } \times \text { Movie-Date Weather } \\
\text { for more than } 3 \text { Days Ahead }\end{array}$ & no & no & no & yes \\
\hline Movie-Date FEs & yes & yes & yes & yes \\
\hline Observations & 52554 & 66819 & 499757 & 514048 \\
\hline
\end{tabular}

Notes: We report the coefficients and standard errors (clustered on the movie-date level) of estimates of (6) via the complementary log-log model described in the text. The set of independent variables includes purchase-date weather conditions (average sunshine duration as a fraction of an hour, average hourly rainfall in $\mathrm{mm}$, and their 14-day moving averages), variables describing expected movie-date weather at the time of purchase, purchase-horizon fixed effects, and movie-date fixed effects. Columns 1 and 2 restrict the data to ticket orders between one and four days ahead of the day of the movie, Columns 3 and 4 estimate (6) using orders up to four weeks in advance. In Columns 1 and 3 we control for expected weather using the variables of the weather forecast (maximum and minimum temperature in degree Celsius, mutually exclusive forecast indicators); the omitted forecast category is "sunny." These variables are set to zero for purchase horizons earlier than four days, for which data on forecasts for the day of the movie is unavailable. In the remaining columns, we proxy for expected movie-date weather by interactions of realized movie-date weather and dummies for the purchase horizon. Level of significance: ${ }^{*} p<0.10,{ }^{* *} p<0.05,{ }^{* * *} p<0.01$. 
Table 10: Event History Estimates of the Effect of Hourly Weather on Ticket Orders per Hour

\begin{tabular}{lccc}
\hline & \multicolumn{3}{c}{ Hourly Ticket Orders (1-4 Days Ahead) } \\
\cline { 2 - 4 } & Daytime & Morning & Afternoon \\
& $(1)$ & $(2)$ & $(3)$ \\
\hline Current Sunshine Duration & $0.13^{* *}$ & $0.15^{*}$ & $0.15^{*}$ \\
& $(0.06)$ & $(0.09)$ & $(0.09)$ \\
Current Rainfall & 0.05 & -0.10 & 0.08 \\
& $(0.04)$ & $(0.12)$ & $(0.05)$ \\
\hline Horizon FEs & yes & yes & yes \\
Hour-of-Day Dummies & yes & yes & yes \\
Movie-Date FEs & yes & yes & yes \\
Observations & 48714 & 29347 & 17787 \\
\hline
\end{tabular}

Notes: We report the coefficients and standard errors (clustered on the movie-date level) of the hourly hazard rate of ticket orders ( 1 to 4 days in advance) estimated by the complementary log log model described in the text. The set of independent variables includes hourly weather conditions (sunshine duration as a fraction of an hour, hourly rainfall in $\mathrm{mm}$ ), as well as purchase-horizon fixed effects, hour-of-day fixed effects, and movie-date fixed effects. Column 1 reports coefficients for all orders between 8 am and $8 \mathrm{pm}$. In the two remaining columns we split the dataset into orders before and after $2 \mathrm{pm}$. Level of significance: ${ }^{*} p<0.10,{ }^{* *} p<0.05,{ }^{* * *} p<0.01$.

individuals who have ordered the ticket on a particular day. To this end, we bring all individual ticket orders on a given date for one particular movie into the person-period format described above. The hourly hazard rate of ticket orders is then estimated using the complementary log-log model; the explanatory variables included in this model are hourly sunshine duration and rainfall as well as purchase-horizon, hour-of-day, and movie-date fixed effects. The empirical model is thus similar in spirit to those Poisson regressions in Section 3.3 which estimate the conditional mean of hourly aggregate orders. One notable difference between the two approaches is, however, that we control for daily conditions (average purchase-date weather, expected movie-date weather) explicitly in the Poisson regressions, while in the event history approach this is achieved via restricting the population at risk to orders on a particular day. To ensure comparability with the count regressions, moreover, we restrict the sample to ticket orders during the daytime, between one and four days ahead of the day of the movie, for the estimations.

The results in Table 10 show that the event history analysis of the purchasing behavior within a day leads to very similar findings as the corresponding Poisson regressions in the main text (Table 5). Customers are estimated to be about 13 to 15 percent more likely to order tickets during an hour in which the sky is completely clear than during an hour in which the sky is completely cloudy. Also, the effect of sunshine duration on the hazard rate of ticket orders seems to be equally strong during the morning and afternoon hours.

\section{B.2. Count Regressions Using the Cross-Sectional Dimension of the Data}

In the main empirical analyses of this paper, we use Poisson panel regressions to estimate the effect of the weather on ticket orders. This empirical approach uses the time variation in the covariates 
for identification (i.e., the change in weather from three to two days before the movie). A nonstandard issue that arises here is, however, that expected ticket orders are non-stationary: they tend to increase for dates closer to the movie's showing. As a consequence, weather and purchasehorizon effects may interact in such a way that for the identification strategy to be valid, the horizon fixed-effects $\delta_{t \tau}$ need to control for the horizon-dependent variation in ticket orders sufficiently well.

To check whether this may be a threat to the identification strategy employed in the main text, we estimate the "cross-sectional" equivalent of model (1), holding the purchase horizon fixed. For this empirical specification, the conditional mean of ticket sales $h$ days before the movie is given by

$$
y_{t h}=\exp \left(\mathbf{W e a t h e r}_{\mathbf{t}}^{\prime} \boldsymbol{\beta}_{\boldsymbol{W}}+\text { Forecast }_{\mathbf{t h}}^{\prime} \boldsymbol{\beta}_{\boldsymbol{F}}+\mathbf{M}_{\mathbf{t h}}^{\prime} \boldsymbol{\beta}_{\boldsymbol{M}}\right) \quad \text { for fixed } h=\tau-t .
$$

Since the purchase horizon $h$ is fixed, there is a single observation for each date of a movie $\tau$. We, hence, cannot control for movie-date characteristics via fixed effects, but instead control explicitly for observable factors via the vector $\mathbf{M}_{\mathbf{t h}}$ consisting of dummies for the movie-date's weekday, the year, and the month. ${ }^{41}$ In the empirical model (7), the effect of weather on ticket orders is identified from "cross-sectional" variation in weather across the dates of the movies for fixed purchase horizons. As such, identification is robust to potential interactions of weather and purchase-horizon effects. This robustness comes at the cost of losing statistical power by only using one observation per date of a movie in the estimations. Also, the "cross-sectional" data seems to exhibit overdispersion, which we take into account by assuming that the ticket orders are distributed according to the negative binomial distribution (of order 2); we hence estimate (7) via the NB2 model. ${ }^{42}$

The "cross-sectional" model (7) is estimated separately for each purchase horizon between one and four days before the movie. As in the main analysis, we control for expected movie-date weather either by including the variables of the weather forecast or by using the realized movie-date weather as a proxy. Table 11 summarizes the results. In general, the coefficients of purchase-date sunshine duration are in a similar range as those in the main specification reported in Table 3; interaction effects hence do not seem to be a relevant concern. Moreover, except for the cross-section of ticket orders four days ahead of the movie, the coefficients tend to be slightly larger when we proxy for expected movie-date weather via its ex post realization. In line with the graphical analysis in Figure 2, Table 11 also suggests that the effect of the weather forecast on ticket orders declines with the deteriorating quality of the forecast. This becomes apparent through the decrease in the predictive power of the forecast variables for earlier ticket orders. In contrast, the positive association between good purchase-date weather and orders remains stable throughout. ${ }^{43}$

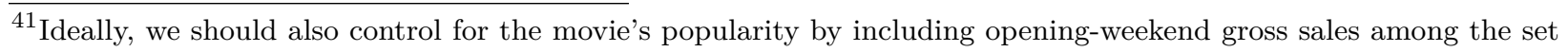
of covariates. However, this data is only available for roughly three-quarters of the movies shown. That being said, the results do not change when gross sales are included.

${ }^{42}$ Assuming that (1) describes the conditional mean of Poisson-distributed ticket orders, ticket orders conditional on the purchase horizon are distributed according to the negative binomial distribution if $\exp \left(\mu_{\tau}+\delta_{t \tau}\right)$ is $\operatorname{Gamma}$ distributed (see Cameron and Trivedi, 1998). Given the flexibility of the Gamma distribution, it is likely that this is a good approximation.

${ }^{43}$ Three days in advance, neither the coefficient of sunshine duration nor that of rainfall is, by itself, statistically significant in the specification that controls for the expected weather via the forecast. Jointly, however, they are,
} 
Table 11: Effect of Purchase-Date Weather on Cross-Sections of Ticket Orders

\begin{tabular}{|c|c|c|c|c|c|c|c|c|}
\hline \multirow[b]{3}{*}{ Avg. Sunshine Duration } & \multicolumn{8}{|c|}{ Purchase-Date Ticket Orders } \\
\hline & \multicolumn{2}{|c|}{1 Day Ahead } & \multicolumn{2}{|c|}{2 Days Ahead } & \multicolumn{2}{|c|}{3 Days Ahead } & \multicolumn{2}{|c|}{4 Days Ahead } \\
\hline & $\begin{array}{l}0.52^{* * *} \\
(0.18)\end{array}$ & $\begin{array}{l}0.82^{* * *} \\
(0.17)\end{array}$ & $\begin{array}{l}0.66^{* * *} \\
(0.21)\end{array}$ & $\begin{array}{l}0.89^{* * *} \\
(0.18)\end{array}$ & $\begin{array}{c}0.33 \\
(0.24)\end{array}$ & $\begin{array}{l}0.61^{* * *} \\
(0.21)\end{array}$ & $\begin{array}{l}0.57^{* * *} \\
(0.21)\end{array}$ & $\begin{array}{c}0.45^{* *} \\
(0.21)\end{array}$ \\
\hline Avg. Rainfall per Hour & $\begin{array}{r}-0.59^{*} \\
(0.32)\end{array}$ & $\begin{array}{c}-0.74^{* * *} \\
(0.28)\end{array}$ & $\begin{array}{c}0.20 \\
(0.32)\end{array}$ & $\begin{array}{c}-0.18 \\
(0.29)\end{array}$ & $\begin{array}{r}-0.45 \\
(0.39)\end{array}$ & $\begin{array}{c}-0.18 \\
(0.34)\end{array}$ & $\begin{array}{c}0.37 \\
(0.37)\end{array}$ & $\begin{array}{c}0.01 \\
(0.34)\end{array}$ \\
\hline Avg. Sunshine Past 14 Days & $\begin{array}{c}0.31 \\
(0.36)\end{array}$ & $\begin{array}{r}0.63^{*} \\
(0.37)\end{array}$ & $\begin{array}{c}-0.15 \\
(0.38)\end{array}$ & $\begin{array}{c}0.21 \\
(0.42)\end{array}$ & $\begin{array}{c}0.16 \\
(0.51)\end{array}$ & $\begin{array}{c}0.53 \\
(0.46)\end{array}$ & $\begin{array}{c}-0.18 \\
(0.52)\end{array}$ & $\begin{array}{c}0.07 \\
(0.48)\end{array}$ \\
\hline Avg. Rainfall Past 14 Days & $\begin{array}{r}-1.38 \\
(1.03)\end{array}$ & $\begin{array}{c}-3.02^{* * *} \\
(0.97)\end{array}$ & $\begin{array}{c}-3.61^{* * *} \\
(1.11)\end{array}$ & $\begin{array}{c}-3.02^{* * *} \\
(1.05)\end{array}$ & $\begin{array}{r}-2.76^{*} \\
(1.42)\end{array}$ & $\begin{array}{r}-1.96 \\
(1.20)\end{array}$ & $\begin{array}{c}-3.63^{* * *} \\
(1.32)\end{array}$ & $\begin{array}{c}-2.83^{* *} \\
(1.19)\end{array}$ \\
\hline Forecast Maxtemp. & $\begin{array}{l}0.15^{* * *} \\
(0.03)\end{array}$ & & $\begin{array}{l}0.14^{\text {*** }} \\
(0.03)\end{array}$ & & $\begin{array}{l}0.10^{* * *} \\
(0.03)\end{array}$ & & $\begin{array}{c}0.05^{*} \\
(0.03)\end{array}$ & \\
\hline Forecast Mintemp. & $\begin{array}{c}0.02 \\
(0.03)\end{array}$ & & $\begin{array}{c}0.01 \\
(0.04)\end{array}$ & & $\begin{array}{c}-0.00 \\
(0.04)\end{array}$ & & $\begin{array}{c}0.02 \\
(0.03)\end{array}$ & \\
\hline Symbol Partly Sunny & $\begin{array}{c}-0.35^{* *} \\
(0.14)\end{array}$ & & $\begin{array}{c}-0.45^{* *} \\
(0.18)\end{array}$ & & $\begin{array}{r}-0.11 \\
(0.21)\end{array}$ & & $\begin{array}{c}-0.57^{* * *} \\
(0.19)\end{array}$ & \\
\hline Symbol T-Storm & $\begin{array}{c}-0.63^{* * *} \\
(0.17)\end{array}$ & & $\begin{array}{c}-0.98^{* * *} \\
(0.19)\end{array}$ & & $\begin{array}{c}-0.46^{* *} \\
(0.22)\end{array}$ & & $\begin{array}{c}-0.54^{* * *} \\
(0.18)\end{array}$ & \\
\hline Symbol Shower & $\begin{array}{c}-1.09^{* * *} \\
(0.18)\end{array}$ & & $\begin{array}{c}-0.52^{\text {*** }} \\
(0.20)\end{array}$ & & $\begin{array}{r}-0.18 \\
(0.24)\end{array}$ & & $\begin{array}{c}-0.28 \\
(0.22)\end{array}$ & \\
\hline Symbol Rain & $\begin{array}{c}-4.04^{* * *} \\
(1.14)\end{array}$ & & $\begin{array}{c}-1.24^{* *} \\
(0.48)\end{array}$ & & $\begin{array}{r}-0.46 \\
(0.73)\end{array}$ & & $\begin{array}{c}-0.32 \\
(0.78)\end{array}$ & \\
\hline Movie-Date Sunshine & & $\begin{array}{l}1.56^{* * *} \\
(0.18)\end{array}$ & & $\begin{array}{l}1.34^{* * *} \\
(0.18)\end{array}$ & & $\begin{array}{l}0.96^{* * *} \\
(0.20)\end{array}$ & & $\begin{array}{l}0.86^{* * *} \\
(0.19)\end{array}$ \\
\hline Movie-Date Rainfall & & $\begin{array}{c}-1.43^{* * *} \\
(0.31)\end{array}$ & & $\begin{array}{c}-0.56^{* *} \\
(0.28)\end{array}$ & & $\begin{array}{c}-0.24 \\
(0.32)\end{array}$ & & $\begin{array}{c}0.01 \\
(0.23)\end{array}$ \\
\hline Year \& Month FEs & yes & yes & yes & yes & yes & yes & yes & yes \\
\hline Movie's Day-of-Week FEs & yes & yes & yes & yes & yes & yes & yes & yes \\
\hline Observations & 393 & 473 & 390 & 472 & 384 & 471 & 383 & 470 \\
\hline
\end{tabular}

Notes: We report the coefficients and robust standard errors from negative binomial regressions of daily ticket orders on purchase-date weather conditions (average sunshine duration as a fraction of an hour, average hourly rainfall in mm, and their 14-day moving averages), expected movie-date weather, either as indicated by the weather forecast (omitted forecast symbol: "sunny") or proxied by realized weather, year and month fixed effects, as well as dummies for the day of the week of the movie's showing. These statistics are reported separately for "cross-sections" of ticket orders between 1 and 4 days in advance; see the empirical model ( 7 ) for details. Level of significance: ${ }^{*} p<0.10,{ }^{* *} p<0.05,{ }^{* * *} p<0.01$. 


\section{How To Distinguish Between Candidate Psychological Mechanisms}

We have argued that it is hard to distinguish between the candidate explanations "consideration set salience," "projection bias," and "extrapolative expectations." A natural question that may arise is whether there are ways to cleanly distinguish between these psychological mechanisms. In this section, we discuss potential ways to, hypothetically, achieve this. The discussion remains hypothetical, because we either lack the statistical power or the data needed to further tease the psychological explanations apart.

Consideration set salience vs. projection bias / extrapolative expectations. By reminding customers of the option of visiting the cinema at times of beautiful weather, consideration set salience affects ticket orders via the size of the demand side. In contrast, projection bias and extrapolative expectations affect the individual purchasing behavior via the weather-related over- or under-estimation of future utility. One possibility of identifying the exact psychological mechanism at work is, hence, to verify that weather on the day of purchase indeed affects individual behavior. Conlin et al. (2007) follow this strategy by including customer fixed effects in their empirical specification, thus using variation in the weather experiences of individual customers for identification. A similar test could, in principle, also employed in this setting. Unfortunately, though, we lack a sufficiently large number of customers who visit the theater frequently enough, so all the statistical analyses are heavily underpowered when customer fixed effects are included.

Instead of looking for evidence regarding the weather dependency of individual behavior, it is also possible to test whether weather affects the size of the demand side. For the case of the movie theater's online ticket orders, this could be achieved by using the number of hits on the webpage that gives a brief description of the movie played on a particular date as a proxy for the number of potential customers. ${ }^{44}$ This data has, unfortunately, not been archived by the cinema.

Given the data available, there thus seems to be no clean way to distinguish between the reminder effect of the weather and weather related distortions of estimated future utility. Instead, one could reiterate the arguments in favor of the salience effect of weather, namely that we are finding the strongest results for the most salient dimension of weather - sunshine - and that the explicit disclaimer about the weather risk on the ticketing should help customers to carefully evaluate their future utility. However, when favoring a salience-related hypothesis, one would also have to accept that good weather leads to the selection of customers with a very high sensitivity to the weather in order to explain the strong increase in the number of erroneously purchased tickets at times of good weather documented in Section 5.1, which is much easier explained by projection bias or extrapolative expectations. Overall, we are hence inclined to conclude that our primary results are consistent with both these psychological mechanisms.

with a $p$-value of 0.07 .

${ }^{44}$ See, for example, http://www.kino-mond-sterne.de/kms.php/pirates-of-the-caribbean-fremde-gezeiten/. 
Extrapolative expectations vs. projection bias. We have already argued in Section 5.3 that the difference between extrapolative expectations and projection bias essentially boils down to two distinct interpretations of the same functional form of the estimated future utility (4). For explaining the weather-dependent purchasing behavior of the theater's customers, both interpretations seem equally plausible. To tease these mechanisms apart, additional data - for example, on the beliefs held by customers - would be needed.

In the survey conducted at the cinema, we collected coarse data on the beliefs about future weather. In particular, question 2 of the survey asked customers about their beliefs regarding the future weather $1,3,5,7$, and 14 days ahead. For each forecast horizon, customers could tick one of the boxes reading "sunny," "partly sunny," "overcast," "rainy," "scattered thunderstorms," and "no statement possible" (see Section D for additional details regarding the survey procedures and the exact question asked). We test whether these stated beliefs are affected by the current weather and/or the weather forecast by estimating the following linear regression

$$
\text { Belief }_{i t}=\text { Weather }_{\mathbf{t}}^{\prime} \boldsymbol{\beta}_{\boldsymbol{W}}+\text { Forecast }_{\mathbf{t} \tau}^{\prime} \boldsymbol{\beta}_{\boldsymbol{F}}+\varepsilon_{i t},
$$

where Belief $i t$ is an index taking the values 5 (for "sunny") to 1 (for "thunderstorms") depending on the box ticked. (Customers, who ticked the box "no statement possible" are excluded from the sample.) We chose this linear index as the dependent variable, because we clearly lack statistical power: the variation in the weather and forecast variables comes from only 13 distinct movie nights during which customers were surveyed.

Table 15 in Appendix E shows that the beliefs regarding tomorrow's weather seem to be correlated with today's weather conditions. There seems to be no correlation between the current weather and the weather beliefs for all the other forecast horizons (3, 5, 7, and 14 days ahead) for which we have extracted these beliefs. However, we reiterate that these correlations should be interpreted with great caution as we have only 13 independent data points of current weather conditions and weather forecasts. This is obviously not enough to draw reliable conclusions regarding the effect of the current weather on customers' beliefs. Finding an environment to distinguish between extrapolative expectations and projection bias hence remains a challenge for future work.

\section{The Survey and the Survey's Results}

The survey was conducted on 13 different movie nights of the 2011 season. The survey had to take place in a leisurely and casual setting which means that we could not interview customers face to face. Instead, we handed out a questionnaire when customers entered the theater, and collected all filled-out questionnaires shortly before the screening started. As a consequence, we had little control over the survey conditions. For example, customers may have filled out the questionnaire in groups of two or more individuals, or may have consulted information sources on their phones when they deemed it necessary to do so.

Below, we provide a list of all the questions that we asked in the survey, together with summary 
statistics of the answers. Since the survey is the only data source in which we observe customers who had purchased their tickets either online or offline (at the box office or at one out of three advance ticket booths), all summary statistics are computed separately for "online" and "offline" customers in order to enable the comparison of both groups. In total, we observed 109 customers who purchased their tickets online, and 334 customers who purchased their tickets offline.

Alternatively, the sample could be split between customers who had bought their tickets one or more days in advance (online tickets can be ordered until $6 \mathrm{pm}$ of the day of the movie) and customers who had bought their tickets on the day of the movie. In our sample, there are 58 customers who purchased advance tickets and 385 who purchased their tickets on the day of the show. To preserve the readability of the tables, we perform this split only for questions 5 and 6 (beliefs regarding the possibility that the theater would sell out), as we refer to these comparisons in the main text. We would like to mention, though, that advance customers seem to be even more similar to same-day customers than online customers are similar to offline customers. The main differences between advance customers and same-day customers are what one might have expected: advance customers are less likely to have considered an alternative to spending the night out (question 10), more likely to have experienced bad weather conditions in the past (heavy rain, question 20), and a larger fraction of them had let their tickets expire in the past due to bad weather (question 21). In addition, advance customers are significantly more likely to be male (question 1).

1. First, we would like to ask you some questions about yourself.

We asked for gender, age, ZIP code, whether customers have internet access, and occupation. Occupation could be written down freely and is thus not reported here. The table below reports the means of the remaining variables for online and offline customers as well as the $p$-value of a $t$-test for the equality of means.

\begin{tabular}{lcccc}
\hline & mean offline & mean online & difference & $p$-value \\
\hline female & $65.9 \%$ & $63.3 \%$ & $2.6 \%$ & 0.63 \\
age in years & 31.7 & 31.7 & -0.0 & 0.97 \\
lives in the greater Munich area & $91.0 \%$ & $93.6 \%$ & $-1.6 \%$ & 0.62 \\
has internet access & $98.7 \%$ & $99.0 \%$ & $-0.3 \%$ & 0.82 \\
\hline
\end{tabular}

2. How is the weather in Munich going to be tomorrow / in 3 days / in 5 days / in 1 week / in 2 weeks?

The purpose of this question is to extract customers' beliefs regarding future weather. For each forecast horizon, they could tick boxes reading either "sunny", "partly sunny," "overcast," "rainy," "scattered thunderstorms," and "no statement possible." Summary statistics for the first five options are not really meaningful, as beliefs are likely to depend on the current forecast and, possibly, the weather conditions on the night of the movie. We have tested whether there is a correlation between the latter variables and the customers' beliefs already in Appendix C. Here, we therefore show the percentage of customers who tick the box "no 
statement possible" for each forecast horizon. A major fraction of the customers seems to be pessimistic regarding their ability to say something about future weather three or more days ahead, reflecting, perhaps, the variable weather conditions in Munich. Moreover, "online" customers seem to be more cautious than "offline" customers.

percentage of customers who tick "no statement possible" by forecast horizon

1 day ahead 3 days ahead 5 days ahead 1 week ahead 2 weeks ahead

\begin{tabular}{llllll}
\hline offline & $1.5 \%$ & $6.2 \%$ & $18.7 \%$ & $32.4 \%$ & $47.5 \%$ \\
online & $1.8 \%$ & $5.6 \%$ & $24.5 \%$ & $42.7 \%$ & $58.3 \%$ \\
\hline
\end{tabular}

3. How often do you check the weather forecast?

\begin{tabular}{cccccc}
\hline & & & once or twice & when I plan weather \\
& daily & every other day & a week & never & related activities \\
\hline offline & $54.1 \%$ & $16.5 \%$ & $12.3 \%$ & $2.1 \%$ & $15.0 \%$ \\
online & $54.1 \%$ & $14.7 \%$ & $14.7 \%$ & $4.6 \%$ & $11.9 \%$ \\
\hline
\end{tabular}

4. If you check the weather forecast: what is your preferred source? (multiple answers possible)

\begin{tabular}{ccccc}
\hline & online weather service & newspaper & radio & TV \\
\hline offline & $77.2 \%$ & $9.6 \%$ & $45.6 \%$ & $34.5 \%$ \\
online & $75.0 \%$ & $6.5 \%$ & $48.1 \%$ & $23.1 \%$ \\
\hline
\end{tabular}

5. How frequently is the weather forecast's prediction correct for the weather...

\begin{tabular}{lcccccc}
\hline & $\begin{array}{c}\text { almost } \\
\text { always }\end{array}$ & $\begin{array}{c}\text { in } 4 \text { out } \\
\text { of } 5 \text { cases }\end{array}$ & $\begin{array}{c}\text { in } 3 \text { out } \\
\text { of } 5 \text { cases }\end{array}$ & $\begin{array}{c}\text { in } 2 \text { out } \\
\text { of } 5 \text { cases }\end{array}$ & $\begin{array}{c}\text { in } 1 \text { out } \\
\text { of } 5 \text { cases }\end{array}$ & $\begin{array}{c}\text { almost } \\
\text { never }\end{array}$ \\
\hline $\begin{array}{l}\text {. tomorrow } \\
\text { offline }\end{array}$ & $48.9 \%$ & $37.2 \%$ & $12.0 \%$ & $0.6 \%$ & $0.0 \%$ & $1.2 \%$ \\
$\quad \begin{array}{l}\text { online } \\
\text { in 2 days }\end{array}$ & $49.5 \%$ & $33.9 \%$ & $14.6 \%$ & $1.8 \%$ & $0.0 \%$ & $0.0 \%$ \\
$\quad$ & & & & & \\
offline & $7.2 \%$ & $41.8 \%$ & $35.4 \%$ & $13.3 \%$ & $0.9 \%$ & $1.2 \%$ \\
$\begin{array}{l}\text { online } \\
\text { in 4 days }\end{array}$ & $5.5 \%$ & $34.9 \%$ & $46.8 \%$ & $11.0 \%$ & $1.8 \%$ & $0.0 \%$ \\
$\quad \begin{array}{l}\text { offline } \\
\text { online }\end{array}$ & $1.8 \%$ & $9.1 \%$ & $34.7 \%$ & $32.6 \%$ & $14.9 \%$ & $6.7 \%$ \\
\hline
\end{tabular}

6. How likely is it that the movie theater is going to be sold out tomorrow shortly before the beginning of the movie, that is, how likely is it that there will be no tickets available at the 
box office shortly before the screening starts?

\begin{tabular}{ccccc}
\hline & very unlikely & unlikely & likely & very likely \\
\hline offline & $34.8 \%$ & $44.5 \%$ & $18.7 \%$ & $1.8 \%$ \\
online & $26.1 \%$ & $42.0 \%$ & $20.5 \%$ & $11.2 \%$ \\
\hline
\end{tabular}

Customers with online tickets are, in general, more worried that the theater sells out. However, this seems to be particularly true for those online customers who order on the day of the movie: The results in the table below indicate that customers with advance tickets and (online and offline) customers who purchased their tickets on the day of the show share a rather similar beliefs regarding whether it is likely that the theater will sell out. (That online customers are more worried that the theater sells out may be a selection issue. If customers are rational and assign a sufficiently high probability to the event that the theater sells out, the optimal choice is to purchase tickets online on the day of the movie.)

\begin{tabular}{ccccc}
\hline & very unlikely & unlikely & likely & very likely \\
\hline same-day customers & $34.2 \%$ & $42.6 \%$ & $19.2 \%$ & $4.0 \%$ \\
advance customers & $22.1 \%$ & $52.6 \%$ & $19.3 \%$ & $5.3 \%$ \\
\hline
\end{tabular}

7. How likely is it that tickets for the movie theater are going to sell out online, that is, how likely is it that there will be no single ticket available at the box office tomorrow evening?

\begin{tabular}{ccccc}
\hline & very unlikely & unlikely & likely & very likely \\
\hline offline & $63.4 \%$ & $25.6 \%$ & $7.8 \%$ & $3.0 \%$ \\
online & $52.3 \%$ & $31.1 \%$ & $11.9 \%$ & $4.6 \%$ \\
\hline
\end{tabular}

There is a similar difference between advance customers' and same-day customers' assessments of the likelihood that tickets sell out online:

\begin{tabular}{ccccc}
\hline & very unlikely & unlikely & likely & very likely \\
\hline day-of customers & $62.0 \%$ & $26.2 \%$ & $8.6 \%$ & $3.1 \%$ \\
advance customers & $51.7 \%$ & $32.7 \%$ & $10.4 \%$ & $5.2 \%$ \\
\hline
\end{tabular}

8. Where did you buy your tickets?

291 customers (out of 441 asked) had purchased their tickets at the box office. While the majority of advance tickets are sold online (108 out of 150), there are three ticket booths at which tickets for the cinema are available. See question 15 for details regarding the sales at the different advance sales locations. 
The table below shows the frequency of advance ticket orders by purchase horizon. (All tickets not sold at the box office are regarded as advance tickets, which is why it is possible to buy advance tickets "today.")

\begin{tabular}{ccccccc}
\hline & today & yesterday & 2 days ago & 3 days ago & 4 days ago & earlier \\
\hline offline & $61.9 \%$ & $16.6 \%$ & $4.7 \%$ & $7.1 \%$ & $2.3 \%$ & $7.1 \%$ \\
online & $62.9 \%$ & $23.1 \%$ & $1.8 \%$ & $2.7 \%$ & $2.7 \%$ & $6.4 \%$ \\
\hline
\end{tabular}

9. Including today, how often have you visited this movie theater so far?

\begin{tabular}{cccc}
\hline & this is the first time & 2 to 5 times & more than 5 times \\
\hline offline & $36.4 \%$ & $41.2 \%$ & $22.3 \%$ \\
online & $37.6 \%$ & $35.7 \%$ & $26.6 \%$ \\
\hline
\end{tabular}

10. If you were not here today, would you have spent the night out in a different way?

Customer could say either yes or no; 44 percent of offline customers and 48 percent of online customers stated that they did not have alternative plans for the night. Customers answering with yes could add in writing, how they would have spent their evening. The most frequent answers are "going for drinks" (33 times), "spending an evening at the beer garden" (24 times), or "going to the movies" (21 times; most probably referring to an indoor movie theater).

11. One final question on how you spend your free time. How often do you ...

\begin{tabular}{|c|c|c|c|c|c|}
\hline & never & $\begin{array}{c}\text { once a } \\
\text { year }\end{array}$ & $\begin{array}{c}\text { twice a } \\
\text { year }\end{array}$ & $\begin{array}{l}\text { once a } \\
\text { month }\end{array}$ & $\begin{array}{l}\text { more } \\
\text { often }\end{array}$ \\
\hline \multicolumn{6}{|c|}{...go to the movies? } \\
\hline offline & $0.9 \%$ & $6.0 \%$ & $37.9 \%$ & $37.9 \%$ & $8.7 \%$ \\
\hline online & $0.0 \%$ & $5.5 \%$ & $46.8 \%$ & $43.1 \%$ & $4.6 \%$ \\
\hline \multicolumn{6}{|c|}{...go to a concert? } \\
\hline offline & $8.8 \%$ & $38.5 \%$ & $41.8 \%$ & $8.8 \%$ & $2.1 \%$ \\
\hline online & $8.3 \%$ & $35.8 \%$ & $47.7 \%$ & $6.4 \%$ & $1.8 \%$ \\
\hline \multicolumn{6}{|c|}{...go to the theater? } \\
\hline offline & $19.8 \%$ & $50.7 \%$ & $23.0 \%$ & $5.5 \%$ & $0.9 \%$ \\
\hline online & $26.6 \%$ & $39.4 \%$ & $25.0 \%$ & $2.7 \%$ & $0.0 \%$ \\
\hline \multicolumn{6}{|c|}{...go to the opera? } \\
\hline offline & $58.2 \%$ & $29.6 \%$ & $9.8 \%$ & $1.5 \%$ & $0.9 \%$ \\
\hline online & $58.3 \%$ & $36.1 \%$ & $3.7 \%$ & $0.9 \%$ & $0.9 \%$ \\
\hline \multicolumn{6}{|c|}{... attend a sports event? } \\
\hline offline & $38.4 \%$ & $32.3 \%$ & $18.9 \%$ & $7.0 \%$ & $3.3 \%$ \\
\hline online & $35.8 \%$ & $34.0 \%$ & $19.3 \%$ & $7.3 \%$ & $3.7 \%$ \\
\hline
\end{tabular}


The following two questions apply only to customers who have purchased their tickets at the box office.

12. Which of the following ways to purchase advance tickets for the outdoor cinema do you know? (multiple answers are possible)

Advance tickets can be purchased online or at one of three ticket booths (we label these booths "booth 1," "booth 2 ," and "booth 3 "). This applies only to customers with "offline tickets," as online tickets are regarded as "advance tickets."

\begin{tabular}{lccccc}
\hline & online & booth 1 & booth 2 & booth 3 & none \\
\hline offline customers & $80.6 \%$ & $26.9 \%$ & $49.7 \%$ & $4.4 \%$ & $10.8 \%$ \\
\hline
\end{tabular}

13. Why did you not purchase an advance ticket? (multiple answers possible)

\begin{tabular}{lr}
\hline & $\begin{array}{r}\text { share of } \\
\text { respondents }\end{array}$ \\
\hline I did not know that there was the possibility of buying tickets in advance & $3.0 \%$ \\
I wasn't sure whether I was going to visit the cinema & $41.8 \%$ \\
It is unlikely for the movie to be sold out & $30.6 \%$ \\
I wanted to wait what the weather was going to be & $62.2 \%$ \\
\hline
\end{tabular}

The following questions apply only to customers who have purchased advance tickets.

14. How many tickets did you buy?

\begin{tabular}{cccccc}
\hline & 1 & 2 & 3 & 4 & more than 4 \\
\hline advance customers & $7.0 \%$ & $65.1 \%$ & $9.3 \%$ & $13.2 \%$ & $6.4 \%$ \\
\hline
\end{tabular}

15. Where did you purchase your ticket?

\begin{tabular}{ccccc}
\hline & online & booth 1 & booth 2 & booth 3 \\
\hline advance customers & $77.9 \%$ & $12.1 \%$ & $7.9 \%$ & $2.1 \%$ \\
\hline
\end{tabular}

16. Did you condition your purchasing decision on the weather forecast?

A small majority (57 percent) of customers conditioned their purchasing decision on the weather forecast. 
17. Do you regret that you purchased tickets in advance?

Only eight customers (5.5 percent) regretted their purchasing decision. The reason all of them gave was that advance tickets are (slightly) more expensive than tickets at the box office. (See footnote 7 for details).

18. Why did you purchase your tickets in advance and not at the box office? (multiple answers possible)

\begin{tabular}{lr}
\hline & share of respondents \\
\hline I was worried that the movie might sell out & $70.3 \%$ \\
The line at the box office is too long & $23.4 \%$ \\
If I don't buy the tickets immediately, I forget it later on & $6.2 \%$ \\
It facilitates the coordination of a larger group & $7.6 \%$ \\
\hline
\end{tabular}

The following questions apply to everyone again.

19. How important are the following factors for you to enjoy a night at the outdoor movie theater (on a 5 point scale ranging from "very important" to "not important at all")?

\begin{tabular}{lccccc}
\hline \multicolumn{2}{c}{$\begin{array}{c}\text { very } \\
\text { important }\end{array}$} & & & & $\begin{array}{c}\text { not important } \\
\text { at all }\end{array}$ \\
\hline the movie shown & & & & \\
offline & $61.7 \%$ & $28.7 \%$ & $8.1 \%$ & $0.9 \%$ & $0.6 \%$ \\
online & $53.8 \%$ & $34.9 \%$ & $6.6 \%$ & $3.8 \%$ & $0.9 \%$ \\
pleasant temperatures & & & & \\
offline $\quad 22.2 \%$ & $41.6 \%$ & $27.2 \%$ & $7.2 \%$ & $1.9 \%$ \\
online $\quad 27.2 \%$ & $44.7 \%$ & $21.4 \%$ & $4.9 \%$ & $1.9 \%$ \\
no rainfall & & & & \\
offline & $53.2 \%$ & $26.6 \%$ & $12.7 \%$ & $5.3 \%$ & $2.2 \%$ \\
online & $54.3 \%$ & $30.5 \%$ & $11.4 \%$ & $1.9 \%$ & $1.9 \%$ \\
good company & & & & \\
offline & $62.7 \%$ & $23.6 \%$ & $7.4 \%$ & $2.8 \%$ & $3.4 \%$ \\
online & $61.2 \%$ & $30.1 \%$ & $5.8 \%$ & $1.0 \%$ & $1.9 \%$ \\
a good seating area & & & & \\
offline & $17.4 \%$ & $35.6 \%$ & $34.4 \%$ & $12.0 \%$ & $0.6 \%$ \\
online & $12.8 \%$ & $49.0 \%$ & $32.3 \%$ & $2.9 \%$ & $2.9 \%$ \\
\hline
\end{tabular}


20. Did you ever have bad luck when visiting an outdoor movie theater? (multiple answers possible)

\begin{tabular}{cccccc}
\hline & & $\begin{array}{c}\text { yes, heavy } \\
\text { no }\end{array}$ & $\begin{array}{c}\text { yes, light } \\
\text { rain }\end{array}$ & $\begin{array}{c}\text { yes, thunder- } \\
\text { storms }\end{array}$ & $\begin{array}{c}\text { yes, it was } \\
\text { cold }\end{array}$ \\
\hline online & $53.6 \%$ & $24.0 \%$ & $14.4 \%$ & $12.0 \%$ & $14.7 \%$ \\
offline & $45.3 \%$ & $32.0 \%$ & $10.4 \%$ & $11.3 \%$ & $14.2 \%$ \\
\hline
\end{tabular}

21. Did you ever let your tickets expire because of bad weather?

\begin{tabular}{ccc}
\hline & yes & no \\
\hline online & $5.9 \%$ & $94.1 \%$ \\
offline & $4.8 \%$ & $95.2 \%$ \\
\hline
\end{tabular}

Two more questions were added at the request of the movie theater's management. The first question asked customers how they had learned about the movie theater. The second question asked for feedback and suggestions for improvement. Customers could answer both questions in writing, which is why we do not report their answers here.

Thank you very much for your participation. Enjoy the movie! 


\section{E. Additional Tables and Figures}

Table 12: Effect of Purchase-Date Weather on Ticket Orders: Robustness

\begin{tabular}{|c|c|c|c|}
\hline & \multicolumn{3}{|c|}{ Ticket Orders (1-28 Days Ahead) } \\
\hline & (1) & $(2)$ & $(3)$ \\
\hline Avg. Sunshine Duration & $\begin{array}{l}0.467^{* * *} \\
(0.071)\end{array}$ & $\begin{array}{l}0.441^{* * *} \\
(0.135)\end{array}$ & $\begin{array}{l}0.487^{* * *} \\
(0.071)\end{array}$ \\
\hline$\times$ I $($ Purchase-Date Fr-Su $)$ & $\begin{array}{c}0.006 \\
(0.008)\end{array}$ & & \\
\hline$\times$ I(Movie-Date Fr-Su $)$ & $\begin{array}{r}0.014^{*} \\
(0.008)\end{array}$ & & \\
\hline$\times \mathrm{I}($ Genre $=$ Drama $)$ & & $\begin{array}{c}0.097 \\
(0.140)\end{array}$ & \\
\hline$\times \mathrm{I}($ Genre $=$ Comedy $)$ & & $\begin{array}{r}-0.030 \\
(0.132)\end{array}$ & \\
\hline Avg. Rainfall per Hour & $\begin{array}{l}-0.369^{* * *} \\
(0.129)\end{array}$ & $\begin{array}{c}0.034 \\
(0.234)\end{array}$ & $\begin{array}{r}-0.183^{*} \\
(0.102)\end{array}$ \\
\hline$\times \mathrm{I}($ Purchase-Date Fr-Su $)$ & $\begin{array}{c}-0.011 \\
(0.013)\end{array}$ & & \\
\hline$\times$ I(Movie-Date Fr-Su $)$ & $\begin{array}{l}0.185^{* * *} \\
(0.034)\end{array}$ & & \\
\hline$\times \mathrm{I}($ Genre $=$ Drama $)$ & & $\begin{array}{r}-0.214 \\
(0.232)\end{array}$ & \\
\hline$\times \mathrm{I}($ Genre $=$ Comedy $)$ & & $\begin{array}{r}-0.244 \\
(0.239)\end{array}$ & \\
\hline \# Tickets Sold Earlier & & & $\begin{array}{c}-0.006^{* *} \\
(0.003)\end{array}$ \\
\hline Avg. Sunshine Past 14 Days & $\begin{array}{l}1.481^{* * *} \\
(0.557)\end{array}$ & $\begin{array}{l}1.513^{* * *} \\
(0.579)\end{array}$ & $\begin{array}{l}1.554^{* * *} \\
(0.510)\end{array}$ \\
\hline Avg. Rainfall Past 14 Days & $\begin{array}{c}-1.366^{* *} \\
(0.554)\end{array}$ & $\begin{array}{l}-1.455^{* * *} \\
(0.557)\end{array}$ & $\begin{array}{c}-1.414^{* *} \\
(0.592)\end{array}$ \\
\hline Horizon FEs & yes & yes & yes \\
\hline Horizon $\times$ Movie-Date Weather & yes & yes & yes \\
\hline Movie-Date FEs & yes & yes & yes \\
\hline Observations & 12790 & 12706 & 12790 \\
\hline
\end{tabular}

Notes: We report the coefficients and standard errors (clustered on the movie-date level) from Poisson panel regressions of (1). The specification is identical to Column 4 of Table 3 except that further independent variables are added in each column. In Column 1, interactions of purchase-date weather variables and indicators that equal 1 when either the day of the movie or the day of purchase was a Friday, Saturday, or Sunday are added. In Column 2, purchase-date weather variables are interacted with indicators regarding the movie's genre as defined by http://www.imbd.com. In Column 3, the number of tickets sold prior to the day of purchase is added to the set of independent variable. Level of significance: ${ }^{*} p<0.10,{ }^{* *} p<0.05,{ }^{* * *} p<0.01$. 
Table 13: Predictive Power of Current Weather and the Weather Forecast

\begin{tabular}{|c|c|c|c|c|c|c|c|c|}
\hline \multirow[b]{3}{*}{ Avg. Sunshine Duration } & \multicolumn{8}{|c|}{ Evening Sunshine Duration } \\
\hline & \multicolumn{2}{|c|}{1 Day into the Future } & \multicolumn{2}{|c|}{2 Days into the Future } & \multicolumn{2}{|c|}{3 Days into the Future } & \multicolumn{2}{|c|}{4 Days into the Future } \\
\hline & $\begin{array}{c}0.118^{* *} \\
(0.054)\end{array}$ & $\begin{array}{c}0.003 \\
(0.061)\end{array}$ & $\begin{array}{c}-0.005 \\
(0.058)\end{array}$ & $\begin{array}{r}-0.017 \\
(0.055)\end{array}$ & $\begin{array}{r}-0.027 \\
(0.056)\end{array}$ & $\begin{array}{r}-0.059 \\
(0.053)\end{array}$ & $\begin{array}{c}0.053 \\
(0.055)\end{array}$ & $\begin{array}{c}0.073 \\
(0.058)\end{array}$ \\
\hline Avg. Rainfall per Hour & $\begin{array}{c}-0.069 \\
(0.063)\end{array}$ & $\begin{array}{c}0.108 \\
(0.082)\end{array}$ & $\begin{array}{c}-0.054 \\
(0.074)\end{array}$ & $\begin{array}{r}-0.006 \\
(0.098)\end{array}$ & $\begin{array}{r}-0.091 \\
(0.074)\end{array}$ & $\begin{array}{r}-0.083 \\
(0.093)\end{array}$ & $\begin{array}{c}0.008 \\
(0.073)\end{array}$ & $\begin{array}{r}-0.054 \\
(0.083)\end{array}$ \\
\hline Avg. Sunshine Past 14 Days & $\begin{array}{c}0.181 \\
(0.113)\end{array}$ & $\begin{array}{c}-0.000 \\
(0.112)\end{array}$ & $\begin{array}{l}0.242^{* *} \\
(0.119)\end{array}$ & $\begin{array}{c}0.072 \\
(0.114)\end{array}$ & $\begin{array}{c}0.186 \\
(0.119)\end{array}$ & $\begin{array}{c}0.136 \\
(0.125)\end{array}$ & $\begin{array}{c}0.044 \\
(0.118)\end{array}$ & $\begin{array}{c}0.014 \\
(0.125)\end{array}$ \\
\hline Avg. Rainfall Past 14 Days & $\begin{array}{c}-0.331 \\
(0.294)\end{array}$ & $\begin{array}{r}-0.230 \\
(0.258)\end{array}$ & $\begin{array}{c}-0.306 \\
(0.304)\end{array}$ & $\begin{array}{c}-0.092 \\
(0.274)\end{array}$ & $\begin{array}{r}-0.519^{*} \\
(0.304)\end{array}$ & $\begin{array}{r}-0.029 \\
(0.288)\end{array}$ & $\begin{array}{c}-0.655^{* *} \\
(0.293)\end{array}$ & $\begin{array}{r}-0.296 \\
(0.289)\end{array}$ \\
\hline Forecast Maxtemp. & & $\begin{array}{l}0.020^{* * *} \\
(0.006)\end{array}$ & & $\begin{array}{c}0.009 \\
(0.008)\end{array}$ & & $\begin{array}{c}0.015^{* *} \\
(0.007)\end{array}$ & & $\begin{array}{c}0.013^{*} \\
(0.007)\end{array}$ \\
\hline Forecast Mintemp. & & $\begin{array}{c}-0.011 \\
(0.008)\end{array}$ & & $\begin{array}{c}0.001 \\
(0.010)\end{array}$ & & $\begin{array}{c}0.002 \\
(0.010)\end{array}$ & & $\begin{array}{c}0.000 \\
(0.008)\end{array}$ \\
\hline Symbol Partly Sunny & & $\begin{array}{c}-0.237^{* * *} \\
(0.052)\end{array}$ & & $\begin{array}{c}-0.328^{* * *} \\
(0.047)\end{array}$ & & $\begin{array}{c}-0.206^{* * *} \\
(0.060)\end{array}$ & & $\begin{array}{c}-0.201^{* * *} \\
(0.058)\end{array}$ \\
\hline Symbol Shower & & $\begin{array}{c}-0.430^{* * *} \\
(0.059)\end{array}$ & & $\begin{array}{c}-0.456^{* * *} \\
(0.061)\end{array}$ & & $\begin{array}{c}-0.439^{* * *} \\
(0.065)\end{array}$ & & $\begin{array}{c}-0.244^{* * *} \\
(0.069)\end{array}$ \\
\hline Symbol Rain & & $\begin{array}{c}-0.663^{* * *} \\
(0.068)\end{array}$ & & $\begin{array}{c}-0.671^{* * *} \\
(0.080)\end{array}$ & & $\begin{array}{c}-0.496^{* * *} \\
(0.108)\end{array}$ & & $\begin{array}{c}-0.363^{* *} \\
(0.155)\end{array}$ \\
\hline Year \& Month FEs & yes & yes & yes & yes & yes & yes & yes & yes \\
\hline Adjusted $R^{2}$ & 0.06 & 0.34 & 0.04 & 0.29 & 0.04 & 0.24 & 0.04 & 0.11 \\
\hline Observations & 473 & 393 & 472 & 390 & 471 & 384 & 470 & 383 \\
\hline
\end{tabular}

Notes: We report the coefficients and robust standard errors of OLS regressions analyzing which variables are able to predict the future duration of sunshine between $5 \mathrm{pm}$ and $7 \mathrm{pm}, 1$ to 4 days ahead (the dependent variable). Candidate predictors (the independent variables) are: current weather conditions (average sunshine duration as a fraction of an hour, average hourly rainfall in mm), the current weather forecast (forecast temperature and weather symbols; only in every other column), current weather trends (sunshine duration and rainfall in the past fortnight), as well as year and month dummies. Level of Significance: ${ }^{*} p<0.10$, ** $p<0.05, * * * p<0.01$. 
Table 14: Customer Characteristics and Purchase-Date Sunshine Duration

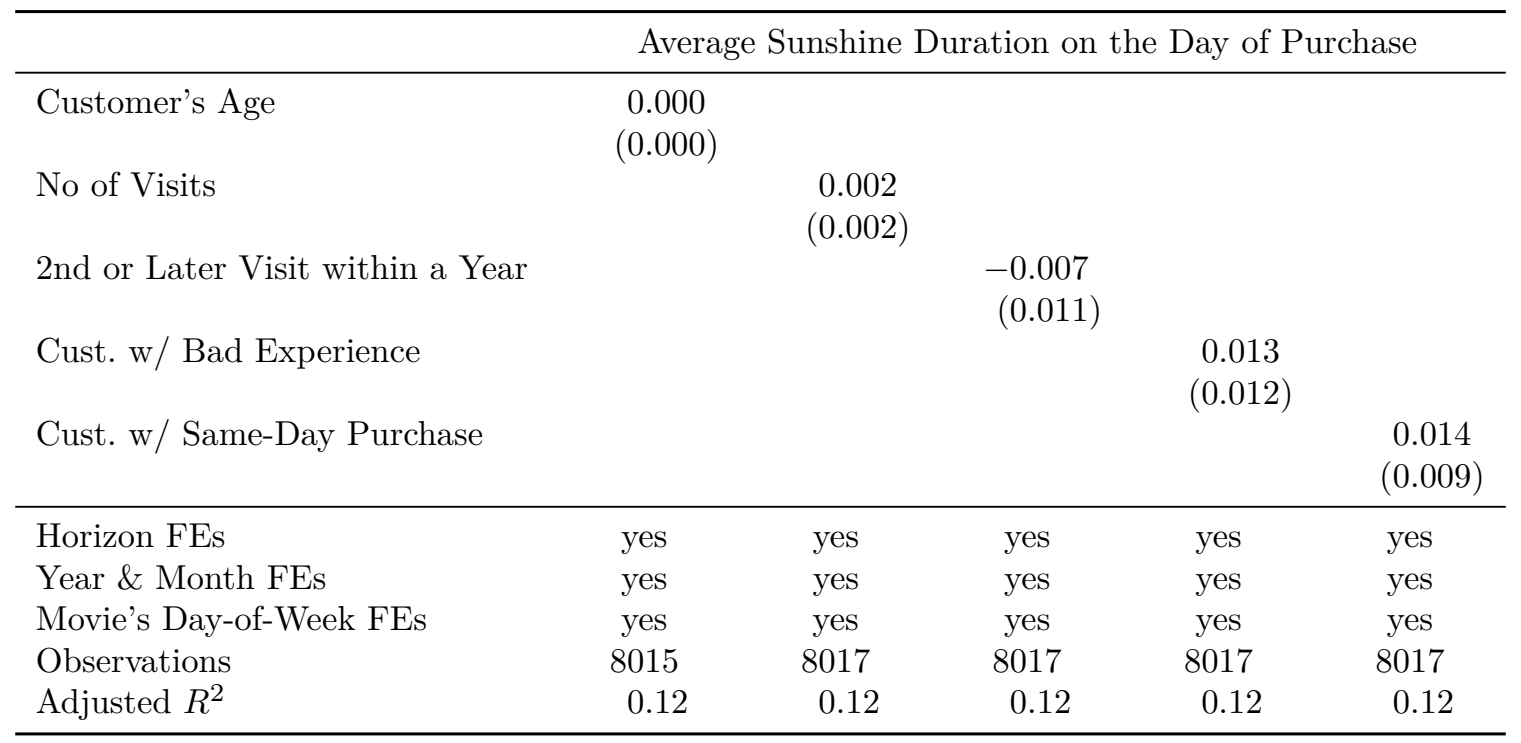

Notes: We report the coefficient and robust standard errors of OLS regressions analyzing whether customer characteristics can explain average purchase-date sunshine duration at the time of advance ticket orders. "2nd or later Visit within a Year," "Cust. w/ Bad Experience," and "Cust. w/ Movie-Date Order" are indicator variables equal to 1 if the customer visits the theater a second or later time in a given year, if the customer had previously ordered tickets for a day of the movie on which there was rainfall during the movie, or if the customer had previously ordered tickets on the day of the movie, respectively. Dummies for the purchase horizon, year and month, and the date of the movie's day of the week are added as independent variables in all regressions. Level of significance: $* p<0.10$, ** $p<0.05, * * * p<0.01$. 
Table 15: Current Weather and Beliefs Regarding Future Weather

\begin{tabular}{|c|c|c|c|c|c|c|c|}
\hline \multirow[b]{3}{*}{ Avg. Sunshine Duration } & \multicolumn{7}{|c|}{ Weather Beliefs (Index Value) } \\
\hline & \multicolumn{2}{|c|}{1 Day Ahead } & \multicolumn{2}{|c|}{3 Days Ahead } & \multirow{2}{*}{$\begin{array}{c}5 \text { Days Ahead } \\
-0.09 \\
(0.19)\end{array}$} & \multirow{2}{*}{$\begin{array}{c}1 \text { Week Ahead } \\
-0.64 \\
(0.48)\end{array}$} & \multirow{2}{*}{$\begin{array}{c}2 \text { Weeks Ahead } \\
-0.64 \\
(0.40)\end{array}$} \\
\hline & $\begin{array}{l}0.75^{* *} \\
(0.26)\end{array}$ & $\begin{array}{l}0.98^{* *} \\
(0.35)\end{array}$ & $\begin{array}{c}0.16 \\
(0.19)\end{array}$ & $\begin{array}{c}0.47 \\
(0.48)\end{array}$ & & & \\
\hline Avg. Rainfall per Hour & $\begin{array}{c}-0.67 \\
(0.39)\end{array}$ & $\begin{array}{c}-0.89 \\
(0.51)\end{array}$ & $\begin{array}{c}0.66 \\
(0.37)\end{array}$ & $\begin{array}{c}-0.14 \\
(0.44)\end{array}$ & $\begin{array}{l}1.78^{* * *} \\
(0.16)\end{array}$ & $\begin{array}{c}-0.45 \\
(0.64)\end{array}$ & $\begin{array}{c}-0.27 \\
(0.86)\end{array}$ \\
\hline Forecast Maxtemp. & $\begin{array}{l}0.39^{* * *} \\
(0.04)\end{array}$ & & $\begin{array}{l}0.26^{* * *} \\
(0.02)\end{array}$ & & & & \\
\hline Forecast Mintemp. & $\begin{array}{l}-0.40^{* * *} \\
(0.08)\end{array}$ & & $\begin{array}{l}-0.17^{* * *} \\
(0.03)\end{array}$ & & & & \\
\hline Symbol Partly Sunny & $\begin{array}{l}0.00 \\
(.)\end{array}$ & & $\begin{array}{c}0.12 \\
(0.20)\end{array}$ & & & & \\
\hline Symbol T-Storm & $\begin{array}{l}-1.15^{* * *} \\
(0.16)\end{array}$ & & $\begin{array}{c}-0.55^{* *} \\
(0.18)\end{array}$ & & & & \\
\hline Symbol Shower & $\begin{array}{l}-0.84^{* * *} \\
(0.11)\end{array}$ & & $\begin{array}{l}-0.96^{* * *} \\
(0.24)\end{array}$ & & & & \\
\hline Symbol Rain & $\begin{array}{l}-2.46^{* * *} \\
(0.24)\end{array}$ & & $\begin{array}{l}0.00 \\
(.)\end{array}$ & & & & \\
\hline Realized Sunshine Duration & & $\begin{array}{l}1.19^{* * *} \\
(0.17)\end{array}$ & & $\begin{array}{l}1.60^{* * *} \\
(0.30)\end{array}$ & $\begin{array}{l}0.55^{* * *} \\
(0.12)\end{array}$ & $\begin{array}{r}-0.66 \\
(0.50)\end{array}$ & $\begin{array}{l}-1.37^{* * *} \\
(0.44)\end{array}$ \\
\hline Realized Rainfall & & $\begin{array}{c}-3.66^{* * *} \\
(0.66)\end{array}$ & & $\begin{array}{r}-0.18 \\
(0.67)\end{array}$ & $\begin{array}{c}-0.73^{* *} \\
(0.30)\end{array}$ & $\begin{array}{r}-0.56 \\
(0.50)\end{array}$ & $\begin{array}{c}-2.78^{* *} \\
(1.21)\end{array}$ \\
\hline Observations & 354 & 431 & 332 & 405 & 333 & 266 & 203 \\
\hline
\end{tabular}

Notes: We report the coefficients and clustered standard errors of OLS regressions analyzing whether current weather can explain customers' beliefs regarding future weather $1,3,5,7$, or 14 days ahead. Beliefs are measured by an index that is an integer between 5 (if weather is expected to be "sunny") and 1 (if "thunderstorms" are expected). The units of observation are customers who have answered question 2 of the survey with a definite belief (for each forecast horizon, they could also answer that they are unable to make a statment regarding expected weather). We control for forecast weather either via the forecast (available only on dates of movies that fall on a weekday and up to 4 days in advance) or its future realization. See Appendix C for details regarding the empirical model and Appendix D for details regarding data collection. Standard errors are clustered on the date when customers were surveyed (at most 13 independent observations). Level of significance: ${ }^{*} p<0.10,{ }^{* *} p<0.05,{ }^{* * *} p<0.01$. 
Figure 10: The Theater

This picture shows the outdoor movie theater. Visitors are sitting in the amphitheater on different rows on flaggings or on wooden boards (the area at the bottom left corner of the picture). The screen is on the left of this picture (not shown).

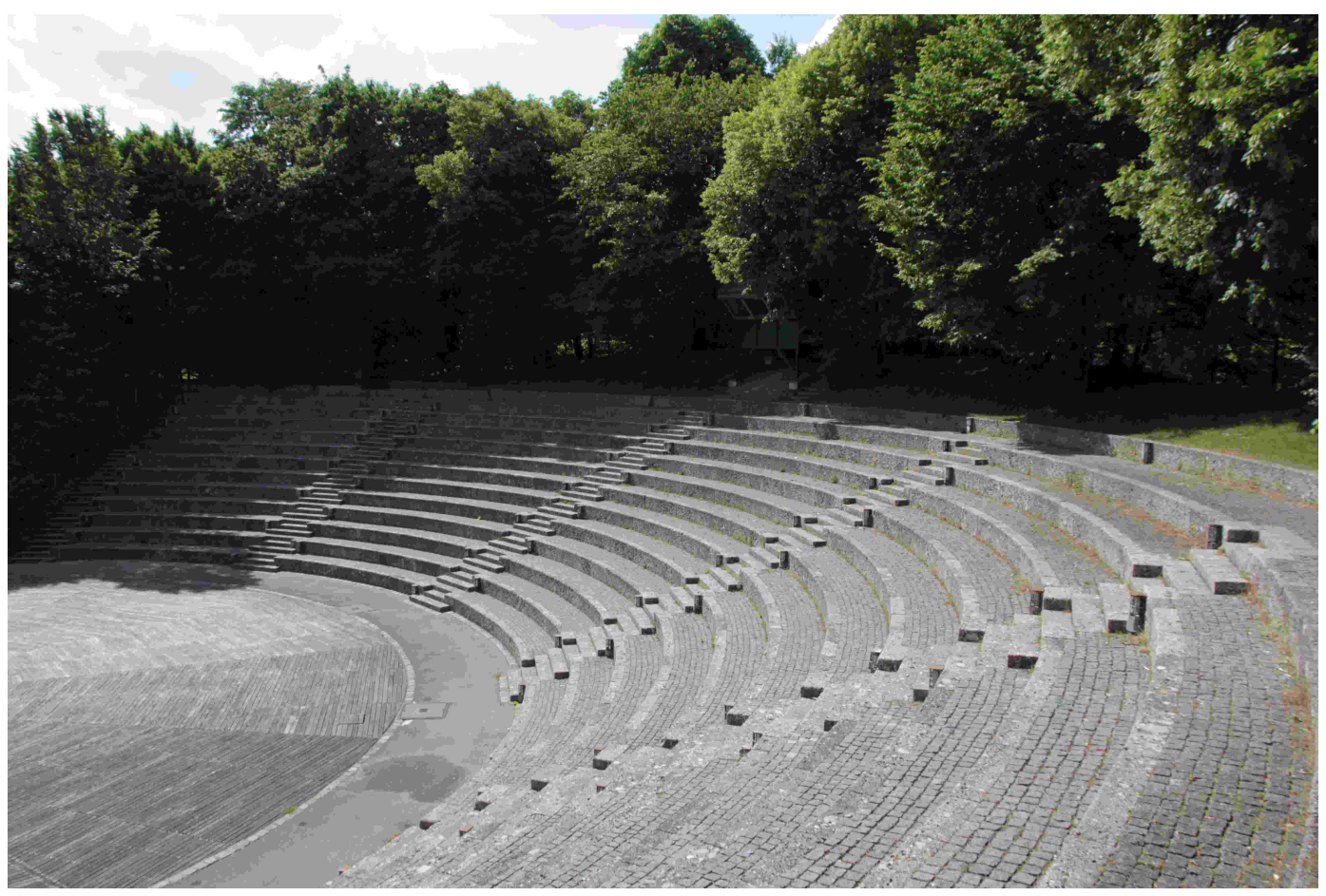

